\title{
Culture, Cognition, and Collaborative Networks in Organizations
}

\section{Citation}

Srivastava, Sameer B., and Mahzarin R. Banaji. 2011. Culture, Cognition, and Collaborative Networks in Organizations. American Sociological Review 76, no. 2: 207-233.

\section{Published Version}

doi:10.1177/0003122411399390

\section{Permanent link}

http://nrs.harvard.edu/urn-3:HUL.InstRepos:12724039

\section{Terms of Use}

This article was downloaded from Harvard University's DASH repository, and is made available under the terms and conditions applicable to Other Posted Material, as set forth at http:// nrs.harvard.edu/urn-3:HUL.InstRepos:dash.current.terms-of-use\#LAA

\section{Share Your Story}

The Harvard community has made this article openly available.

Please share how this access benefits you. Submit a story.

Accessibility 


\title{
Culture, Cognition, and Collaborative Networks in Organizations
}

\author{
Sameer B. Srivastava, Harvard University \\ Mahzarin R. Banaji, Harvard University \\ Running Head: Culture, Cognition, and Collaborative Networks \\ Word Count: 12,000 (including abstract, text, footnotes, and references) \\ Harvard Business School / Harvard Graduate School of Arts \& Sciences \\ Mahzarin R. Banaji, Richard Clarke Cabot Professor of Social Ethics
}

Direct all correspondence to:

Sameer B. Srivastava

Joint Program in Sociology \& Organizational Behavior

Morgan Hall T-69

Boston, MA 02163

ssrivastava@hbs.edu

617-895-8707

Additional Contact Information:

Department of Psychology

Harvard University

33 Kirkland Street

Cambridge, MA 02138

mahzarin_banaji@harvard.edu

Acknowledgements: We thank the $A S R$ reviewers, Max Bazerman, Frank Dobbin, Robin Ely, Filiz Garip, Richard Hackman, Peter Marsden, Chris Muller, Erin Reid, Toby Stuart, and Andras Tilcsik for valuable feedback and suggestions on prior drafts. We also acknowledge the support of Christopher Dial, Mike Diodato, Sean Draine, John Galvin, and Bill Simpson. Any remaining errors in the paper are our own. Financial support from the Harvard Business School and the Edmund J. Safra Center for Ethics is gratefully acknowledged.

Keywords: Culture; cognition; social networks; organizations; collaboration; boundaryspanning; dual-process models; exponential random graph models; Implicit Association Test.

October 29, 2010 


\title{
Culture, Cognition, and Collaborative Networks in Organizations
}

\begin{abstract}
This paper examines the interplay of culture, cognition, and social networks in organizations with norms that emphasize cross-boundary collaboration. In such settings, social desirability concerns can induce a disparity between how people view themselves in conscious (deliberative) and less conscious (automatic) cognition. These differences have implications for the resulting pattern of intra-organizational collaborative ties.

Based on a laboratory study and field data from a biotechnology firm, the authors find that: (a) people consciously reported more positive views of themselves as collaborative actors than they appeared to hold in less conscious cognition; (b) less conscious collaborative-independent self-views were associated with the choice to enlist organizationally distant colleagues in collaboration; and (c) these self-views were also associated with a person's likelihood of being successfully enlisted by organizationally distant colleagues (i.e., of supporting these colleagues in collaboration). By contrast, consciously reported collaborative-independent self-views were not associated with these choices. The study contributes to our understanding of how culture is internalized in individual cognition and how self-related cognition is linked to social structure through collaboration choices. It also demonstrates the limits of self-reports in settings with strong normative pressures and represents a novel integration of methods from cognitive psychology and network analysis.
\end{abstract}

October 29, 2010 


\section{INTRODUCTION}

Recent years have seen a surge of interest in the interrelationships among culture, cognition, and social structure - particularly the structure that is reflected in social networks. Whereas early research in this tradition tended to emphasize the causal role of networks in shaping beliefs and cognitive orientations (e.g., Carley 1991; Walker 1985), a growing body of work suggests that culture - as manifested in individual tastes (Lizardo 2006), cognitive frames (McLean 1998), and worldviews (Vaisey and Lizardo 2010) - can also influence the size and composition of personal networks (for a review, see Pachucki and Breiger 2010). ${ }^{1}$

The search for mechanisms that link culture, cognition, and social structure has led a growing cadre of sociologists to engage more actively with cognitive psychology (Cerulo 2002; Cerulo 2010; DiMaggio 1997; DiMaggio 2002; Martin 2000; Morgan and Schwalbe 1990; Schwarz 1998). In particular, a core insight from cognitive psychology - that human cognition occurs through a mix of more conscious (or deliberative) and less conscious (or automatic) thinking and feeling - has served as a basis for sociological research on topics as wide-ranging as violence (Cerulo 1988), role enactment (Danna Lynch 2007), morality in decision making (Vaisey 2009), and political ideologies (Martin and Desmond 2010).

In this tradition, the present paper examines the interplay among culture, cognition, and social networks in differentiated organizations with norms that emphasize cross-boundary collaboration. In such settings, social desirability concerns can lead people to conform to collaborative norms, even when doing so does not fit their underlying disposition (Goffman 1959; Reynolds and Herman-Kinney 2003). We examine the consequences of this dynamic for how people view themselves - in both deliberative and automatic cognition - and for the pattern

\footnotetext{
${ }^{1}$ A distinct line of research on homophily (e.g., Lazarsfeld and Merton 1954; McPherson, Smith-Lovin, and Cook 2001) has also recognized that similarity in values, attitudes, and beliefs - i.e., "value homophily" - can serve as the basis for interpersonal attraction and network formation.
} 
of collaborative network ties they establish within the organization. We pay particular attention to ties that span organizational boundaries (i.e., across departments and levels of the organizational hierarchy) because - across a variety of settings - such bridging ties have been associated with higher levels of individual status attainment and organizational outcomes (Burt 1992; Fleming and Waguespack 2007; Tsai and Ghoshal 1998).

Building conceptually on the sociological literature that has engaged with cognitive psychology, we also introduce a novel methodological extension. Sociologists have pioneered a variety of methods for measuring meaning systems (for a review, see Mohr 1998); however, when it comes to the measurement of less conscious cognition, researchers have tended to continue relying on self-reports (e.g., Vaisey 2009; Vaisey and Lizardo 2010). Although selfreports obtained through forced-choice surveys may involve less deliberation than interviews, considerable evidence from psychology suggests that even forced-choice surveys can be distorted in contexts governed by social desirability. That is, people are sometimes unaware of, or unwilling to report, their underlying beliefs - including their views of themselves (Banaji and Greenwald 1994; Fiske and Taylor 2007; Nisbett and Wilson 1977). A variety of tools are now available to assess the attitudes, beliefs, and self-concepts that reside in less conscious cognition (for a review, see Wittenbrink and Schwarz 2007). This paper represents an initial attempt to address longstanding sociological questions (e.g., who collaborates with whom?) using methods traditionally used to study less conscious cognition and organizational networks. In so doing, we believe that it opens the door for a new level of cross-disciplinary exchange.

Integrating a technique widely used to study less conscious, or automatic, mental states (i.e., a timed categorization exercise, which is described below) and the tools of network analysis, we examine three related research questions: (a) In organizations with strong 
collaborative norms, to what extent do consciously reported (deliberative) views of the self as a collaborative actor diverge from less conscious (automatic) self-views? (b) To the extent that they do, which of these two forms cognition - deliberative or automatic - is more strongly associated with a person's choice to enlist organizationally distant colleagues in collaboration? (c) On the flip side, which form of self-related cognition is more strongly associated with a person's likelihood of being successfully enlisted by organizationally distant colleagues (i.e., of supporting these colleagues in collaboration)?

In addressing these questions, the study contributes to our understanding of how culture is internalized in human cognition, explicates the role of self-related cognition in motivating collaborative action and shaping social structure, and highlights the limitations of self-reports in contexts governed by strong normative pressures. It also identifies a promising new avenueless conscious self-views - in the search for factors associated with network formation and points to new directions in research on social identity and self and other perception.

\section{THEORY}

\section{Collaborative Organizational Cultures and Social Desirability}

We define collaboration as help or support that individuals within organizations seek from and provide to one other toward the accomplishment of work-related objectives. We draw a conceptual distinction between two facets of collaboration: (a) enlisting colleagues in the accomplishment of one's own work objectives; and (b) supporting colleagues in the achievement of their work objectives. Our definition stresses the act of choosing to enlist (in the former case) or support (in the latter case) another colleague in work activity. It therefore excludes programmatic interaction (e.g., routine encounters in regularly scheduled staff meetings) and 
coordination that occurs outside of an interactional context (e.g., synchronized work or production schedules).

Collaboration of this form has long been recognized as the lifeblood of differentiated organizations, which need to integrate activities across functional, divisional, geographic, and hierarchical boundaries (Blau 1970; Lawrence and Lorsch 1967; Thompson 1967). Yet collaboration across horizontal boundaries (e.g., functions, divisions, departments) often proves elusive because of barriers such as misaligned goals and performance criteria (Walton and Dutton 1969), divergent interpretive schemes (Dougherty 1992), inter-unit competition (Tsai 2002), and incompatible language systems (Bechky 2003). At the same time, collaboration across vertical boundaries (e.g., hierarchical levels) can prove challenging because of perceived and actual differences in power, resources, and status across hierarchical levels (Astley and Sachdeva 1984; Fombrun 1983). ${ }^{2}$

To help overcome these barriers, organizations often adopt and actively promote an organizational culture that stresses cross-boundary collaboration. This culture of collaboration can be expressed in artifacts (e.g., formalized decision processes that stress consultation among work units), espoused beliefs (e.g., broadly disseminated values statements that trumpet collaboration), and underlying assumptions (e.g., taken-for-granted notions that working successfully with colleagues in other units is key to getting ahead in the organization) (Schein 1985). Once established, such a culture can create strong pressures for people to present

\footnotetext{
${ }^{2}$ Although the sources of difficulty vary between horizontal and vertical boundary spanning, both forms of collaboration are typically more difficult than collaboration within departments or at the same hierarchical level. Our arguments therefore pertain generally to collaboration between organizationally distant colleagues (i.e., including colleagues separated by horizontal distance, as well as those separated by vertical distance).
} 
themselves to others in a manner consistent with collaborative norms (e.g., expressing an interest in getting input or 'buy-in' from a colleague, even when that input is unwanted). ${ }^{3}$

\section{Cognition about the Self as a Social Actor}

The self-presentational dynamics triggered by a strong collaborative culture have implications for views of the self as a social actor. In particular, we suggest that people in organizational settings have a self-view that reflects their orientation toward more collaborative or more independent action. We refer to this orientation as the collaborative-independent self-concept (Gecas 1982; Markus 1977; Markus and Kunda 1986; Rosenberg 1979; Stryker 1987). ${ }^{4}$

Consistent with various formulations of dual-process theory (for a review, see Evans 2008) - which suggests that cognition occurs through a mix of more conscious, or deliberative, and less conscious, or automatic, thinking and feeling - we argue that the collaborative selfconcept resides in both cognitive modes. We refer to the more conscious form as the explicit collaborative self-concept (ECS) and the less conscious form as the implicit collaborative selfconcept (ICS).

With respect to ECS, we argue that a hegemonic collaborative culture can constrain the toolkit of symbols, stories, rituals, and worldviews available for people to make sense of and justify their own behavior (Swidler 1986; Swidler 2001). As a result, people in such organizations will tend to frame their interactions in collaborative terms - including some interactions that were routine or even overtly uncooperative. That is, they will justify their

\footnotetext{
${ }^{3}$ We follow Coleman (1988: S104) in conceiving of these collaborative norms as "prescriptive" - i.e., reinforced by "social support, status, honor, and other rewards."

${ }^{4}$ We follow Rosenberg (1979: 7) in conceiving of the self-concept as the "the totality of an individual's thoughts and feelings having reference to himself as an object." The self-concept is often distinguished from self-schema (Markus 1977), which refer to stable attributions about a particular aspect of the self (e.g., whether one is a more collaborative or more independent organizational actor). Although we are technically focused on the latter, we use the more generally recognized term, self-concept. The conceptual distinction between the two is not of material interest given our emphasis on only one aspect of the self-concept. For brevity, and given our focus on collaboration choices, we also use the term, collaborative self-concept, interchangeably.
} 
actions - at least in their more conscious thoughts - in the language of collaboration, even when an objective observer of their behavior would not share this conviction. Support for this proposition comes from a study of self-reported conflict management styles of managers in large organizations: of the five styles studied, the collaborating style was most susceptible to social desirability bias (Thomas and Kilmann 1975).

By contrast, insights from cognitive science suggest that ICS reflects intuitive selfknowledge, which accumulates gradually through experience, is slow to change, and is less sensitive to short-term fluctuations in one's thinking (Lieberman, Jarcho, and Satpute 2004). Because it is based on cumulative experience and cannot be readily altered through ex-post justification of choices, ICS - we contend - provides different, and potentially better, information about a person's collaborative propensity than ECS.

Within organizations that have strong collaborative norms, we are therefore likely to find limited variability in measures of ECS (which will tend to correspond to the organizational norm of collaboration). By contrast, measures of ICS, which will tend to reflect the full range of underlying dispositions in the population, will vary more substantially. For those individuals whose underlying disposition favors more independent, rather than collaborative, action, measures of ICS will therefore tend to diverge from measures of ECS.

\section{Collaborative Self-Concept and the Choice to Enlist Others in Collaboration}

To draw a connection between the collaborative self-concept and a person's choice to enlist colleagues in collaboration, we build on Vaisey's (2009) dual-process model of culture in action. Vaisey distinguishes between "discursive" and "practical" modes of cognition. ${ }^{5}$ The former is used to justify or make sense of a person's choices. It is most evident in the narratives people tell when interviewed about the rationale for their behavior. Because people have access to more

\footnotetext{
${ }^{5}$ These modes correspond to ECS and ICS, respectively.
} 
bits and pieces of culture - e.g., worldviews and values - than they can practically use and because the elements of culture that people collect are often contradictory, Vaisey - building on Swidler (1986; 2001) - argues that the "discursive" mode does not generally motivate human action. By contrast, he contends that the "practical" mode is linked to motivation and predicts subsequent choices. Research in cognitive psychology similarly suggests that implicit self views can motivate the pursuit of behavioral goals consistent with those views (Bargh, Gollwitzer, LeeChai, Barndollar, and Trotschel 2001). We therefore expect that ICS will be associated with the choice to enlist certain colleagues in collaboration. By contrast, we do not expect to find a link between ECS, which has a more tenuous connection to motivation, and collaboration choices.

The challenge of seeking collaborators from other organizational units and at different hierarchical levels is counterbalanced by the personal and career benefits of forging boundaryspanning ties. For example, a new boundary-spanning tie might enable a person to occupy a position of brokerage between two otherwise disconnected departments or between senior management and junior technical people; such brokering positions have been associated with various forms of career success (Burt 1992). Furthermore, boundary spanning ties can be valuable even when they are not associated with brokerage positions (Fleming and Waguespack 2007). In choosing whom to enlist in collaboration, people therefore face a tradeoff: ties to organizationally distant colleagues may be more valuable but are also more difficult to build and maintain.

If ICS is associated with intuitive self-knowledge, which accumulates gradually through cumulative experience, then people who are more implicitly collaborative will also tend to be 
experienced collaborators. For these individuals, the tradeoff will more likely favor the selection of organizationally distant colleagues as collaborators. ${ }^{6}$ Thus, we expect:

\section{Hypothesis 1: In organizations governed by strong collaborative norms, the implicit collaborative self-concept will be positively associated with the choice to enlist organizationally distant colleagues (i.e., those in other departments and at different hierarchical levels) in collaboration.}

\section{Collaborative Self-Concept and the Choice to Support Others in Collaboration}

We now address the flip side of the collaboration coin: how do people choose whom to support in collaborative work? This choice can be disaggregated into two steps: a colleague must request a person's help or support, and the person must cooperate with the request. On the surface, one might not expect to find any association between a person's collaborative selfconcept and the first step (i.e., colleagues' choices to request help or support from the person). That is, people might be expected to hold private their collaborative self-concepts, rendering them undetectable to others. To the extent that the collaborative self-concept "leaked" to others, one might expect ECS, rather than ICS, to do the leaking. After all, how can ICS become known to others when people are not fully aware of it themselves?

Yet we argue exactly this point. Our expectation is grounded in Goffman's (1959) observation that, even as people manage their self-presentation to accentuate certain idealized

\footnotetext{
${ }^{6}$ Although we expect to find an association between ICS and the enlistment of both proximate and distant colleagues in collaboration, we expect the motivational link to be more evident in the case of distant colleagues. Motivational complexity is known to moderate the link between implicit cognition and the pursuit of goals, with multiple or competing goals that people typically have with close contacts serving to attenuate the link (Shah 2003). Because people are more likely to have multiple or competing goals with organizationally proximate colleagues (with whom they come into contact for a variety of reasons that are not related to collaboration), we expect to find a stronger association between ICS and collaboration with organizationally distant colleagues.
} 
qualities, they can inadvertently "give off" expressions to others that are more in line with their underlying self than with the character they are performing. Underlying dispositions can leak to others through non-verbal behavior, which can be difficult to control even when people actively manage their self-presentation (for a review, see DePaulo 1992). Thus, others can often become aware of one's essential character even when one does not overtly communicate it or even tries to mask it. Empirical support for this notion comes from research on cooperation choices in social dilemma experiments. People who were themselves cooperative were able to identify and chose to interact with strangers who were cooperative - despite the fact that they had no direct knowledge of others' propensities to cooperate (Brosig 2002; Frank, Gilovich, and Regan 1993). Just as the nouveaux riches and autodidacts reveal themselves to others through their habitus (Bourdieu 1986), so we suggest that one's underlying collaborative disposition can be detected by others even when one is not consciously aware of it. In organizational settings, ICS will therefore be associated with a person's likelihood of being asked for help or support by colleagues. Because it is linked to motivation, ICS will also be associated with that person's likelihood of complying with such requests. By contrast, because ECS is more susceptible to distortion from social desirability pressures and has a more tenuous link to motivation, we do not expect ECS to be informative in colleagues' choices to request help or support from an individual or in that person's choice to cooperate with the request.

We further suggest that the collaborative signals people send will often disseminate across organizational boundaries (e.g., through the reputations that people develop or through organizational processes such as performance and talent management that transmit this information). For example, a person known for putting organizational interests ahead of individual or group interests can become known in other departments as someone who will be 
sympathetic to and supportive of requests for help from the department. Similarly, a senior leader who develops a reputation for being overly directive with junior colleagues or for taking, rather than sharing, credit for joint accomplishments will not be frequently sought out for help or support by junior colleagues. We therefore expect:

\section{Hypothesis 2: In organizations governed by strong collaborative norms, the implicit collaborative self-concept will be positively associated with a person's likelihood of being successfully enlisted by organizationally distant colleagues (i.e., of supporting people in other departments and at different hierarchical levels) in collaboration.}

\section{METHOD}

\section{Research Setting}

We tested these hypotheses in the context of a mid-sized biotechnology firm that employed approximately one thousand people. Because of the strong functional affiliations defined by its formal organizational structure, and because its leadership team continually stressed the importance of cross-functional collaboration, the firm was well suited to studying the implications of social desirability pressures for boundary-spanning collaboration. The company had a profitable marketed product and a portfolio of molecules at various stages of development. It was organized along functional lines and included three Research \& Development (R\&D) units - Discovery, Non-Clinical Sciences, and Clinical Development; one Commercial unit, which included both Marketing and Sales; and a corporate support group (e.g., Legal, Human Resources). Each of these units contained a number of departments. Our study focused on the 
R\&D and Commercial functions, as collaboration within and between these groups was widely considered critical to achieving the company's business objectives.

\section{Sample and Data Collection Procedure}

Because over $90 \%$ of employees worked in the R\&D and Commercial functions, with many people having job roles that were not relevant to the study of cross-boundary collaboration, we enlisted the heads of R\&D and Commercial - as well as their Human Resource representatives to help identify the target population for this study. We started by considering all 254 job titles in R\&D and Commercial. We then excluded three categories of job titles: (a) administrative support roles (e.g., "Administrative Coordinator," “Administrative Associate," "Fleet Administrator," "Executive Coordinator"); (b) field sales and other job roles that were primarily about external, rather than internal, interaction (e.g., "Senior Sales Specialist," "Government Policy and Relations Director"); and (c) individual contributor roles (e.g., "Documentation Associate," "Quality Assurance Specialist," "Scientist I / II"). We worked iteratively with the department heads and Human Resources to ensure that these exclusions were made on a consistent basis across the R\&D and Commercial functions (e.g., applying consistent definitions of individual contributor roles). The 127 job titles that remained all involved at least some level of cross-boundary collaboration (i.e., active provision or receipt of help and support beyond programmatic, routine, or chance interaction). That is, the people occupying these roles were at reasonable risk of enlisting and supporting organizationally distant colleagues in collaboration. The sampling approach was therefore consistent with our theoretical focus on boundaryspanning networks. We invited all employees who held one of the 127 job titles to participate in the study. Because some job titles were held by more than one person, there were a total of 174 people invited. 
Participants were recruited in two stages. They first received a joint email from the heads of R\&D and Commercial, informing them of the study. We then followed up with a second email that invited them to participate in the study. We also informed them that their participation was voluntary and that both their participation and individual responses would both remain confidential - i.e., known to us but not to anyone within the company.

Of the 174 employees, we received responses from 118 (68\% total response rate). Of these individuals, 97 provided complete responses (56\% complete response rate). The 97 who provided complete responses had the following profile: average age (43.4 years); average tenure in the firm (4.67 years); average salary grade ( 81 on a scale that ranges from 20 to 120 ); gender composition (56\% men); educational background ( $48 \% \mathrm{PhDs}$ or MDs); and racial / ethnic composition ( $84 \%$ white). The 97 respondents were not significantly different (based on $t$ test comparisons) from non-respondents in terms of age, tenure, salary grade, gender, and educational background; there was, however, a modest yet statistically significant difference in the proportion of whites among respondents versus non-respondents ( $84 \%$ versus $77 \%$ ).

For the individual-level analyses reported below, we included the 97 individuals who provided complete responses to test Hypothesis 1 and the 106 people who provided either complete responses or who were only missing responses to the network survey (i.e., their nominations of others as collaborators) to test Hypothesis 2. The nine with missing nominations of others were at equal risk of being named as collaborators by their colleagues as the 97 who completed the network survey. Thus, it was appropriate to include them in the analyses related to Hypothesis 2. For the dyad-level analyses reported below, we included only the 97 individuals with complete responses to ensure a comparable risk set of naming and being named by others. 
Study participants received a link to an on-line survey and timed categorization exercise (described below) designed to measure ICS. Half the participants received the timed exercise prior to the survey, while the other half took it after the survey. There were no significant differences in the responses of these two groups or their likelihood of providing complete responses. In addition, we collected demographic and job role data from the company's human resource information systems.

\section{Measures - Collaborative Network}

We asked respondents to identify key members of their collaboration network using a standard name-generator question: "Who are the people at [Company] whose help, support, or cooperation you have successfully enlisted toward the accomplishment of your objectives?" (Ibarra 1995) There were no restrictions on the number of names that respondents could provide. Once the survey had closed, we manually matched up the names with the company's human resources system to address misspellings and the use of nicknames.

This question generated the response variables for both individual-level and dyad-level analyses. For the individual-level analyses, the response variables were counts of: (a) the number of people enlisted in collaboration in other departments; (b) the number of people enlisted in collaboration at other hierarchical levels (i.e., at different salary grades, which are described in further detail below); (c) the number of people supported in collaboration (i.e., how many times the respondent was named by others) in other departments; and (d) the number of people supported in collaboration at other hierarchical levels. ${ }^{7}$ The first two measures pertained to Hypothesis 1, while the latter two corresponded to Hypothesis 2. For the dyad-level analyses,

\footnotetext{
${ }^{7}$ In network analysis terms, these measures are variations of outdegree (i.e., the number of collaborators a respondent named) and indegree (i.e., the number of colleagues who named the respondent as a collaborator).
} 
the response variable was an indicator, set to 1 if a directed tie existed between a dyadic pair and to 0 otherwise. ${ }^{8}$

\section{Measures - Implicit Collaborative Self-Concept}

To assess the implicit collaborative self-concept, we used the Implicit Association Test (IAT) procedure (Greenwald, McGhee, \& Schwartz, 1998). The IAT is the most widely used instrument for measuring aspects of implicit cognition (Wittenbrink and Schwarz 2007). Best known for its use in the study of prejudice and discrimination (for a review, see Quillian 2006), the IAT has also been widely used in studies of the self-concept. ${ }^{9}$ Although some studies have shown that IAT responses can be influenced by environmental factors and can vary to some extent across repeated trials (Karpinski and Hilton 2001; Lowery, Hardin, and Sinclair 2001; Mitchell, Nosek, and Banaji 2003), the IAT has been shown to have acceptable psychometric properties in self-concept research (Schnabel et al. 2007).

The IAT requires respondents to rapidly sort words representing different categories into one of two groupings of categories. The procedure assumes it is easier, and therefore takes less time, to sort items that are associated by some feature that is readily discerned in the respondent's mind than items that are not associated in this manner. For example, to assess implicit preferences with respect to age, the IAT procedure might ask people to sort words associated with the categories "Old," "Young," "Good," and "Bad." Subjects would encounter two configurations of these categories - one in which "Old" is paired with "Good" and "Young" is paired with "Bad" and one with the opposite configuration. Subjects would then sort, as rapidly as possible while limiting the number of mistakes, stimuli associated with each of the

\footnotetext{
${ }^{8}$ Ties were "directed" in the sense that we accounted separately for cases when Person $\mathrm{i}$ named Person $\mathrm{j}$ as a collaborator and cases when Person j named Person i as a collaborator.

${ }^{9}$ For critiques of the IAT technique, see Arkes and Tetlock (2004) and Tetlock and Mitchell (2009). For responses to these critiques, see Jost et al. (2009), Greenwald et al. (2009), and Banaji, Nosek, and Greenwald (2004).
} 
four categories (e.g., "Joyful" as a stimulus for "Good" and "Elderly" as a stimulus for "Old"). The researcher would then compare the time it took subjects to correctly sort stimuli in each of the two configurations. The differences in time would provide an indication of the less conscious associations that exist in subjects' minds. For example, if it took a subject significantly less time to correctly sort stimuli when "Good" was paired with "Young" and "Bad" with "Old" than when he or she encountered the opposite configuration, the researcher could infer that the subject held, in less conscious cognition, a more positive association toward the "Young" category than toward the "Old" category. In addition to assessing relative preferences, the IAT has been used extensively to study the association of other attributes (beyond the general qualities of good and bad) with social groups and with the self. These measures are referred to as implicit stereotypes and the implicit self-concept, respectively (see Greenwald and Banaji 1995 for a review of terms and definitions).

In our study, the IAT was configured to obtain a measure of the implicit self-concept with respect to the terms "Collaborative" and "Independent." Participants classified stimulus words related to the categories of "Me" and "Not Me" with two attributes of "Collaborative" and "Independent." The stimuli used to represent the attribute of "Collaborative" were: "Coordination," "Joint," "Working Together," and "Collaboration." Likewise, for the attribute of "Independent," we used: “Autonomous," "Solo," Self-Sufficient," and "Independent." The stimuli representing the category of "Me" were: "I," "Me," "Mine," and "Self." For the category of "Not Me," we used: "They," “Them," "Other," and "Theirs."

As is standard practice, this IAT involved two separate configurations of the four categories: (a) "Collaborative" paired with "Me" and "Independent" paired with "Not Me"; and (b) "Collaborative" paired with "Not Me" and "Independent" paired with "Me." One category 
pairing was placed on the left side of the participant's screen and the other on the right side. Randomly selected stimuli (from the set of sixteen noted above) then flashed in the middle of the screen. Respondents were asked to indicate with a left or right key stroke the construct pairing to which each stimulus belonged. There were 80 such trials. See Figure 1 for a schematic representation of this procedure as it appeared on respondents' computer screens. The IAT, which we implemented through an on-line software program (Millisecond Software 2006), measured the time (in milliseconds) it took participants to categorize each stimulus and kept track of errors in classification. For readers unfamiliar with the IAT, demonstration tests are available at www.implicit.harvard.edu.

\section{- Figure 1 about here -}

Consistent with prior research (Lane et al. 2007), we undertook several steps to improve the quality of IAT responses. Before each new configuration, respondents learned the associations between stimuli and categories through a training trial. In these trials, one category (e.g., "Me") was on the left side of the screen, and its counterpart (e.g., "Not Me") was on the right side. Randomly selected stimuli (drawn from the eight for these two constructs) flashed on the screen for respondents to categorize. In addition, we balanced the trials across left and right sides of the screen: in 40 of the 80 trials "Collaborative" paired with "Me" was on the left side of the screen and in the other 40 it was on the right side. There were no significant differences in responses across these balanced groups. To address potential measurement error from trials in which respondents were distracted or interrupted in the middle of the study, we deleted all trials greater than 10,000 milliseconds. Similarly, to address the possibility that respondents who were simply trying to rush through the study and not paying attention to stimuli presented, we eliminated subjects if more than $10 \%$ of their trials had response latencies below 300 
milliseconds. We also considered an additional basis for exclusion: the number of misclassified stimuli. Adding a 200 millisecond penalty for incorrect categorization did not yield any significant differences in results. We therefore did not include such a penalty in our analysis. After making these adjustments, we calculated for each subject a difference score:

$$
\mathrm{d}=\left(\mathrm{T}_{1}-\mathrm{T}_{2}\right) / \sigma_{\mathrm{p}}
$$

where:

$\mathrm{T}_{1}=$ mean response latency for Collaborative - Not Me vs. Independent $-\mathrm{Me}$ $\mathrm{T}_{2}=$ mean response latency for Collaborative $-\mathrm{Me}$ vs. Independent $-\mathrm{Not} \mathrm{Me}$ $\sigma_{\mathrm{p}}=$ pooled standard deviation across all 80 trials

In line with previous usage, we contend that this difference score reflects a person's collaborative-independent self-concept in implicit cognition. Higher values suggest a stronger implicit association of the self with collaborative, rather than independent, attributes. Lower scores imply the opposite association.

We pilot tested the collaborative-independent IAT procedure in a laboratory study involving 93 university students. The objectives of the pilot test were to ascertain whether participants understood the concepts sufficiently well to perform this particular classification task, to assess whether the data generated by the procedure were in line with other comparable studies, and to determine whether the IAT was providing the same or different information from self-reported collaborative tendencies. After completing the IAT, subjects were given three hypothetical scenarios that involved making a choice of how many people to enlist in collaboration from one's own group and from a different group. As expected, the IAT-based measure of ICS was only weakly correlated ( $\mathrm{r}=0.11$, not significant) with our five-item measure of ECS. Finally, we tested whether ICS or ECS predicted the number or type of collaborators selected in the three hypothetical scenarios. Controlling for differences in stage of education, gender, and ethnicity, ICS predicted the total number of collaborators chosen, but not the 
proportion of out-group collaborators chosen. By comparison, ECS predicted neither the number nor composition of collaborators selected. Overall, the laboratory study gave satisfactory evidence of the construct validity of the IAT measure we used in the field setting. (See Appendix A for more information about the laboratory study).

\section{Measures - Control Variables}

Our measure of ECS in the field study was derived from the following survey question: "In general, what is your preferred way of working - independently or collaboratively?" Responses could range from 7 ("strongly prefer working collaboratively") to 1 ("strongly prefer working independently").

The survey also included a question that we used to control for the level of task interdependence in a given job role: "How dependent are you on colleagues in [the other function] for success in your role?" Responses could range from 1 ("extremely dependent") to 5 "not at all dependent." We reverse coded these responses so that higher values would represent a greater level of interdependence.

For the models (described below) using individual-level data, we also included the following variables from the company's human resource systems as controls: the log of the respondent's salary grade (ranging from 20 to 120), the log of the respondent's tenure with the firm (in years), functional affiliation (indicator with $R \& D=1$, Commercial=0), gender (indicator

with male $=1$, female $=0$ ), educational attainment (indicator with $\mathrm{MD} / \mathrm{PhD}=1$, other $=0$ ), and ethnicity (indicator with white $=1$, other $=0$ ). For the models using dyad-level data, we included five indicators: same function (e.g., both in R\&D); same gender; same education (e.g., both holding an MD / PhD); same ethnicity; and same location (i.e., building and floor).

\section{Measures - Identification with and Relative Preference for Own Function}


Finally, to assess the extent of misalignment between ICS and ECS, we constructed two other measures that could serve as points of comparison: relative identification with and relative preference for the two functions ( $\mathrm{R} \& \mathrm{D}$ and Commercial). We chose these comparisons because considerable prior research has established that people tend to identify with and favor their own organizational subunit (for a review, see Hogg and Abrams 2003). In organizational settings, there is little reason to expect misalignment between implicit and explicit measures of group identification or liking. In fact, people are often encouraged to affiliate with, and tend to have shared identities (e.g., similar educational background or occupational affiliation) with, colleagues in their own subunit. Thus these measures provided a useful benchmark against which to compare the misalignment in beliefs about a person's collaborative tendencies.

For relative identification, we used a modified version of the IAT procedure already described. For the "R\&D" category, we used the following stimuli: "Molecule," "Scientist," “Laboratory," "Dose Response," "Experiment," "Research,” and "Development." For the "Commercial" category, the stimuli were: "Forecast," "Customer," "Pricing," "Product Promotion," "Revenue," "Marketing," and "Sales." These stimuli were selected in consultation with the heads of R\&D and Commercial and pre-tested to ensure that they captured the associations made by people in both groups. To assess identification, we used the "Me" and "Not Me" categories described above, along with the same stimuli. We calculated a measure of implicit relative identification by comparing the time it took subjects to categorize stimuli when "R\&D" was paired with "Me" and "Commercial" with "Not Me" to the time it took when "R\&D" was paired with "Not Me" and "Commercial" with "Me." We also developed a selfreported measure of relative identification based on the difference in responses to two questions 
that asked about the strength of respondents' identification with each function (on a 4 point scale ranging from "completely" to "not at all").

For relative preference, our constructs were "Good," - the stimuli for which were: "Joy," "Love," "Peace," "Wonderful," "Pleasure," "Glorious," "Laughter," and "Happy" - and "Bad," the stimuli for which were: "Agony," "Terrible," "Horrible," "Nasty," "Evil," "Awful,"

"Failure," and "Hurt." To calculate a measure of implicit relative preference, we compared the time it took subjects to categorize stimuli when "R\&D" was paired with "Good" and "Commercial" with "Bad" to the time it took when the constructs were reversed. We also constructed a self-reported measure based on responses to three questions - two of which asked how "warmly" or "coldly" respondents felt toward each function (on a 7 point scale) and one which asked about respondents' preferences for working with each function (with 1 representing "strong" preference for one function, 7 representing "strong" preference for the other function, and 4 representing no preference).

\section{Analytical Approach}

We conducted two sets of analyses. The first used individual-level data. The response variables were all count measures - i.e., number of organizationally distant colleagues enlisted or supported in collaboration. To address potential over-dispersion in these measures, we fitted negative binomial regression models. ${ }^{10}$

The second set of models used dyad-level data (i.e., a 97x97 matrix representing whether a tie existed or did not exist between all ordered pairs of colleagues). The focus on dyad-level collaboration choices required that we contend with the non-independence of observations. ${ }^{11} \mathrm{We}$

\footnotetext{
${ }^{10}$ We also fitted Poisson models, which produced comparable results to the ones reported below.

${ }^{11}$ For example, if Person i named Person $\mathrm{j}$ as a collaborator, then - by the principle of reciprocity - Person $\mathrm{j}$ might also be more likely to name Person i. In this case, the two observations of reported collaboration between Person $i$ and Person $\mathrm{j}$ would not be independent of one another.
} 
therefore used exponential random graph models (also referred to as ERGM or p* models), which explicitly take into account the dependence relationships that exist within the network e.g., mutuality, or the propensity for ties to be reciprocated; transitivity, or the tendency for friends of friends to become friends themselves; and stars, or the popularity of certain actors. These models assume that the observed network is but one realization of a network generation process that could, in principle, have produced other networks. They enable the researcher to ask: how unusual is a particular feature of the observed network relative to the features found in simulated networks drawn from a sample space of networks? Thus, from a single observation of a network, they allow inferences to be drawn simultaneously about multiple factors that could be associated with the likelihood of a tie existing between two given individuals: features of the network structure (e.g., the general tendency toward reciprocity), characteristics of the initiator of a tie (e.g., the salary grade of the person who makes the collaboration choice), characteristics of the target of a tie (e.g., the salary grade of the person about whom a collaboration choice is made), and joint characteristics of the initiator and target (e.g., whether or not the two people are at the same salary grade).

Fitting an exponential random graph model consists of three steps, which we implemented using the PNet software tool (Wang, Robins, and Pattison 2008). First, the model is estimated (typically including features of the network structure and hypothesized characteristics of actors) by comparing the observed network to a large number of simulated networks. Parameter estimates are expressed as conditional log-odds -i.e., the change in the log-odds of a tie being present in response to an increase in a given network statistic. Next, convergence statistics for each parameter are inspected. These convergence statistics, which are expressed as t-ratios, help assess whether the estimates from the first step satisfy the 
requirements of maximum likelihood estimation. ${ }^{12}$ Finally, after obtaining a model with satisfactory convergence statistics for all parameters, the researcher assesses the model's goodness-of-fit. In this third step, the average value of network statistics not in the model for the sample of simulated networks is compared to their observed values. This approach represents a rather stringent test of goodness-of-fit: the model is considered to fit well if it reproduces features of the network that were not used to construct it (for further information on the guidelines for fitting ERGMs, see Morris, Handcock, and Hunter 2008; O'Malley and Marsden 2008; Robins, Pattison, Kalish, and Lusher 2007; Robins, Pattison, and Wang 2009; Snijders, Pattison, Robins, and Handcock 2006). ${ }^{13}$ (See Appendix B for further background about ERGMs and details of the procedure we followed to estimate the models reported on below.)

To test our main hypotheses in this dyadic framework, we constructed two indicators of organizational distance - Different Department (set to 1 when two people worked in different departments and to 0 otherwise) and Different Grade (set to 1 when two people were at different salary grades and to 0 otherwise). We then interacted these indicators with the ICS of the tie initiator (i.e., the person potentially enlisting a colleague) and the ICS of the target (i.e., the person potentially being enlisted, or supporting someone else, in collaboration). The initiator interaction terms (i.e., Initiator's ICS x Different Department and Initiator's ICS x Different Grade) corresponded to Hypothesis 1, while the target interaction terms (i.e., Target's ICS x Different Department and Target's ICS x Different Grade) corresponded to Hypothesis 2.

\footnotetext{
${ }^{12}$ These t-ratios are not the same as the ratio of a parameter estimate to its standard error that is typically reported in regression analyses. Rather, they are a diagnostic for whether the estimation process has converged sufficiently. The t-ratio assesses the hypothesis that the average value of a parameter from the simulations equals the corresponding observed network statistic. If the model has converged, there should be very little evidence against the hypothesis. That is, lower t-ratios suggest better convergence, with the threshold of $95 \%$ confidence corresponding to $|\mathrm{t}|<.10$.

${ }^{13}$ Goodness of fit simulations also produce t-ratios for each parameter. In this case, a model is considered to fit well if $|\mathrm{t}|<.10$ for all parameters that were included in the model and $|\mathrm{t}|<2.0$ for most, if not all, parameters not included in the model.
} 


\section{RESULTS USING INDIVIDUAL-LEVEL DATA}

Table 1 reports descriptive statistics and correlations for the key variables in the field study. The implicit collaborative self-concept had a statistically significant positive correlation with the number of colleagues enlisted in collaboration from other departments (i.e., outdegree - to other departments), the number of colleagues supported in collaboration (i.e., indegree), the number of colleagues supported in collaboration from other departments (i.e., indegree - from other departments), and the number of colleagues supported in collaboration at different salary grades (i.e., indegree - from other salary grades). By contrast, the explicit collaborative self-concept was not significantly correlated with any of the network measures.

\section{- Table 1 about here -}

Figure 2 shows that ICS and ECS were less strongly correlated than were the other two pairs of implicit and explicit measures we used as points of comparison: relative identification with and relative preference for one's own function relative to the other function. Whereas the correlation between ICS and ECS was 0.16 (not significant), the corresponding correlations for the identification and preference measures were statistically significant and considerably higher: $0.46(\mathrm{p}<.001)$ and $0.37(\mathrm{p}<.001)$, respectively. Furthermore, as Figure 3 shows, the distribution of responses for ECS was considerably skewed, while, as Figure 4 depicts, ICS was more evenly distributed. Appendix C depicts a scatterplot matrix of the relationship between ICS and ECS. These findings - when considered alongside the comparable results reported in the laboratory study - generally support the claim that social desirability pressures can distort self-reports of the collaborative self-concept.

- Figure 2 about here -

- $\quad$ Figure 3 about here - 


\section{- Figure 4 about here -}

Table 2 reports the results of the negative binomial models used to test Hypothesis 1: that ICS was associated with the number of organizationally distant colleagues enlisted in collaboration (i.e., with outdegree - to colleagues in other departments and at different salary grades). In Model 1, the response variable was the number of colleagues enlisted in collaboration from other departments. Consistent with expectations, ICS was a significant covariate with a positive coefficient. By contrast, ECS was not significant. Ethnicity - White was also significant and had a positive coefficient, perhaps reflecting greater power, status, or resources possessed by this group which aided in enlisting others in collaboration. One other variable that is typically associated with power, status, and resources - Log Salary Grade - was positive but not statistically significant. In Model 2, the response variable was the number of colleagues enlisted in collaboration at a different salary grade. Two covariates were statistically significant: Function - R\&D and Task Interdependence. The negative coefficient for Function R\&D may have reflected a more hierarchical work culture among laboratory-trained scientists in that function. One interpretation for the negative coefficient for Task Interdependence is that it served as a proxy for power or resources. That is, people with greater power or resources felt less dependent on other functions and could also wield that power to enlist colleagues' help or support. Both ICS and ECS had positive coefficients but were not significant. Taken together, the results in Table 2 provide partial support for Hypothesis 1: ICS was significantly associated with the number of horizontally distant - but not vertically distant - colleagues enlisted in collaboration.

\section{- Table 2 about here -}


Table 3 reports the results of the negative binomial models used to test Hypothesis 2: that ICS was associated with the number of organizationally distant colleagues supported in collaboration (i.e., with indegree - from colleagues in other departments and at different salary grades). In Model 3, the response variable was the number of colleagues supported in collaboration from other departments. Again, consistent with expectations, ICS was significant and had a positive coefficient. By contrast, ECS was not significant. Log Salary Grade was also significant and had a positive coefficient, likely reflecting the attractiveness of senior colleagues (who presumably enjoyed high status or had access to power and resources) as prospective collaborators. In Model 4, the response variable was the number of colleagues supported in collaboration at different salary grades. Five covariates were statistically significant: ICS, Gender - Male, Education - MD / PhD, Log Salary Grade, and Function - R\&D. Taken together, these results suggested support for Hypothesis 2.

- Table 3 about here -

\section{RESULTS USING DYAD-LEVEL DATA}

Tables 4 and 5 report results of the Exponential Random Graph Models used to provide supplemental tests of Hypotheses 1 and 2. The two tables cover different dimensions of organizational distance: Model 5 focused on horizontal boundary spanning, while Model 6 addressed vertical boundary spanning. Both models had acceptable convergence statistics $(|t|<.1)$ for each parameter and satisfactory goodness-of-fit in subsequent simulations we conducted $(|t|<.1$ for all parameters included in the model; $|\mathrm{t}|<2$ for all but a couple of the parameters not included in the model). In both models, five network structural characteristics were statistically significant: Arc (the baseline tendency to form ties), Reciprocity (the tendency for ties to be 
reciprocated), and three higher-order dependence terms (Path Closure, Cyclic Closure, and Multiple Two-Paths). (See Appendix B for an interpretation and visual representation of these structural covariates.) The level of task interdependence of the sender was significant, with a negative coefficient. That is, consistent with the results from Model 2, people who reported being less dependent on the other function also reported enlisting a larger number of colleagues. In addition, the salary grade and tenure of the target (i.e., the person about whom a collaboration choice was made) were significant and had a positive coefficient. That is, more senior people and those with longer tenure in the organization were more likely to be enlisted by others. The dyadic covariates suggested evidence of gender and education-based homophily (a tie was more likely when the initiator and target shared the same gender or had the same level of educational attainment) and propinquity (a tie was more likely when the initiator and target worked in the same office building and floor).

With respect to Hypothesis 1, one of the two relevant interaction terms - Different Grade x Initiator's ICS (in Model 6) - was significant with a positive coefficient. The other term Different Function x Initiator's ICS (in Model 5) - had a positive coefficient but was not significant. With respect to Hypothesis 2, both of the relevant interaction terms - Different Department x Target's ICS (in Model 5) and Different Grade x Target's ICS (in Model 6) - were significant and had positive coefficients. Taken together, these analyses provided corroborating support for Hypothesis 2. They provided partial support for Hypothesis 1. In contrast to the individual-level analyses, however, the dyad-level analyses showed greater support for the role of ICS in the choice to enlist vertically, rather than horizontally, distant colleagues.

- Table 4 about here -

- Table 5 about here - 


\section{DISCUSSION AND CONCLUSION}

This study provides new insight into the interplay of culture, cognition, and social networks in organizations with norms that emphasize cross-boundary collaboration. In such settings, social desirability concerns can induce a disparity between how people view themselves in conscious (deliberative) and less conscious (automatic) cognition. These differences have implications for the resulting pattern of collaborative ties. In both a laboratory and field setting, we found evidence of divergence between people's explicit (consciously reported) collaborative selfconcept (ECS) and their implicit (less conscious) self-concept (ICS). In the field setting, the latter was associated with a person's choice to enlist organizationally distant colleagues in collaboration, whereas the former was not. Intriguingly, the choice to support others in collaboration (i.e., be successfully enlisted by organizationally distant colleagues) was associated with ICS, but not with ECS. That is, counter to what we might expect, colleagues' collaboration choices were associated with an aspect of self-cognition about which a person may not have been fully aware.

These findings raise some questions, to which we next turn. First, we provide a possible explanation for the fact that we found more consistent support for Hypothesis 2 (that ICS is linked to the choice to support organizationally distant colleagues) than for Hypothesis 1 (that ICS is linked to the choice to enlist organizationally distant colleagues). The measures used to test Hypothesis 1 were variations of outdegree (i.e., the number of network members named by the survey respondent). Survey-based measures of outdegree are known to suffer from expansiveness bias - the tendency for respondents to vary in the number of reported ties (Feld and Carter 2002) - and have relatively low reliability (Zemljic and Hlebec 2005). By contrast, indegree measures - the number of times a person was named by others (which corresponded to 
Hypothesis 2) - have relatively high reliability. This difference in reliability may have accounted for the divergence in findings. Given the laboratory study finding - that ICS was positively associated with the number of collaborators selected in hypothetical scenarios - it would be useful in future research to explore how ICS relates to more reliable indicators of outdegree (e.g., as measured through archived electronic communications).

Next, we address the reverse causal explanation: that one's position in the network structure determines one's less conscious self-views. Although the cross-sectional nature of our field study did not allow us to rule out this possibility, the positive association found in the laboratory study between ICS and the number of collaborators subsequently chosen in hypothetical scenarios suggests that the reverse causal story cannot fully account for our findings. (See Appendix A for details.) We suspect that network position and ICS are codetermined. Longitudinal studies, perhaps using actor-driven network models (Steglich, Snijders, and West 2006), are needed to understand their co-evolution. Such research could also identify other contextual factors that shift ICS over time (e.g., organizational and occupational mobility).

In addition, our study design did not allow us to observe other individual-level factors such as personality traits (e.g., extraversion or likability) and skills - that could be implicated in collaboration choices. The laboratory study (see Appendix A) did include two individual difference measures that have been associated with certain kinds of networks: individualismcollectivism (Wagner 1995; Wagner and Moch 1986) and the tertius iungens orientation (Obstfeld 2005). Neither measure was strongly correlated with ICS or with subjects' collaboration choices. Nevertheless, we cannot rule out the possibility that ICS was only serving as a proxy for some other omitted personality characteristic such as extraversion. Future 
research should more closely examine the link between ICS and other individual difference constructs and control for the latter in statistical models. Another limitation to address in future research is our somewhat coarse-grained measure of task interdependence. This measure could be refined by assessing interdependence between each pair of colleagues, rather than in aggregate between functions; such a measure would better account for role-based factors that influence collaboration choices.

Finally, we suggest the need to examine whether these results generalize to other workplace settings. For example, can people detect one another's collaborative dispositions in organizations where work mostly gets done remotely or through virtual teams? Is ICS implicated in choices to collaborate with temporary or off-shore workers? What role does ICS play in collaboration with external actors (e.g., competitors, alliance partners, regulators)?

\section{Contributions}

We believe that this study makes a number of conceptual and methodological contributions to research on culture, cognition, and social structure. First, it clarifies how people internalize culture - in the form of organizational norms - in contexts governed by social desirability. Widespread and strongly sanctioned norms can limit the available toolkit of symbols, stories, rituals, and worldviews that people use to justify and make sense of their actions (Swidler 1986; Swidler 2001). As a result, in deliberative - or "discursive" - cognition, they are more likely to frame interactions in terms that are aligned with prescribed norms even when an objective observer of their behavior would not share this view. By contrast, less conscious self-views - or "practical" cognition - will be less susceptible to distortion. In such settings, dual-process models will therefore prove especially useful in understanding how culture shapes the way people see themselves (Evans 2008; Vaisey 2009). 
The study also clarifies the role of self-related cognition in motivating collaborative action and influencing social structure (as expressed in collaborative networks). Our findings suggest that the implicit collaborative self-concept is implicated in choices to form ties that span organizational boundaries - both horizontal (across departments) and vertical (across hierarchical levels). Network researchers have long sought to identify individual-level factors associated with the tendency to form network ties, in general, and boundary-spanning ties, in particular (see, for example, Burt, Jannotta, and Mahoney 1998; Mehra, Kilduff, and Brass 2001; Obstfeld 2005; Totterdell, Holman, and Hukin 2008). Although a few network scholars have examined the relationship between cognition and networks (see, for example, Casciaro 1998; Kilduff and Krackhardt 1994; Krackhardt 1987; Krackhardt 1990; Krackhardt and Kilduff 1999), this study represents - to the best of our knowledge - the first to delve into the role of less conscious cognition. It suggests a promising new avenue - implicit self-views - in the search for factors that are associated with network formation and change.

In addition, the study has implications for research on self and other perception (e.g., Felson 1985; Felson and Reed 1986; Ichiyama 1993; Miyamoto and Dornbush 1956). For example, Yeung and Martin (2003) examine the conditions under which people can influence others' perceptions of them and when, consistent with Cooley's "looking glass self hypothesis," their self-views come to shaped by their perceptions of how others view them (Cooley 1902). They conclude that "self-perception involves the internalization of the perspectives of others - at least those whom we see as ascendant over us" (Yeung and Martin 2003: 873). In similar fashion, a study of newly married couples showed that views initially held by the higher status spouse were more likely to influence the partner's subsequent self-views (Cast, Stets, and Burke 1999). Our results suggest the need to complicate these stories by accounting for differences in 
self-views that reside in deliberative versus automatic cognition. The latter may less susceptible to influence by others' perceptions. In our setting, others' choices to collaborate with an individual were linked to the person's less conscious self-view. Conversely, these prior studies suggest the need to complicate our own account. For example, do status distinctions play a role in how one thinks of oneself implicitly? What are the conditions under which one can detect another's underlying disposition? To what extent do status differentials influence one's ability to do so?

The insights from this study also suggest promising new directions for various strands of identity research (e.g., Burke 2006; Burke and Stets 2009; Hogg and Ridgeway 2003; McCall and Simmons 1978; Stryker and Burke 2000). For example, how do identities that reside below conscious awareness form, change over time, and become salient in a given context? Do the hierarchies of identity that reside in conscious cognition differ from those that exist in less conscious cognition? How do people verify one another's identities when those identities are implicitly, rather than explicitly, held? How do multiple identities, which are held in automatic cognition and share dimensions of meaning, influence one another in the process of identity change? Along the same lines, prior work on the role of values in shaping personal identities (e.g., Gecas 2000; Hitlin 2003) could be extended to consider potential differences in identity change that occurs in deliberative versus automatic cognition. Do values adopted because of social conformity pressures, for example, have a greater effect on identities held in one form of cognition than in the other?

With respect to research methods, the study highlights the limitations of survey research as a tool for assessing automatic cognition. In contexts governed by social desirability, selfreports can be significantly distorted and bear little relation to observed patterns of behavior. As 
an alternative to self-reports, we develop and validate a technique - which can be used in future research - for assessing the implicit collaborative self-concept. This technique can be readily extended to other implicit self-views (e.g., whether one sees oneself as a local or cosmopolitan, insider or outsider, explorer or exploiter) that may play a role in organizational action. It may also serve as a useful complement to established methods, such as the semantic differential (Burke and Tully 1977) and role-identity salience (Callero 1985; Callero 1992), for the measurement of role identities.

In conclusion, we believe that this study underscores the value of continued engagement between sociology and cognitive psychology. It represents a further integration of not only concepts (e.g., dual-process theory, self-concept, cultural toolkits, boundary-spanning networks) but also methods (e.g., the Implicit Association Test and exponential random graph models) in the cross-disciplinary investigation of culture, cognition, and social structure. 


\section{Appendix A - Details of Laboratory Study}

\section{Study Design:}

93 students - majoring in psychology, economics, or a natural science - at a large, private university in the Northeast participated in the study. After reading and signing an informed consent form, study participants completed an Implicit Association Test to assess their implicit collaborative self-concept (ICS). (This IAT was nearly identical to the one used in the biotechnology firm and described in the main body of the paper.) We then presented participants with a hypothetical collaboration vignette, assigning students to either the Marketing Club or the

Science Club (based on their major):

- Imagine, as a [psychology, economics, science] student, that you are attempting to market and develop a new computer product. Created by the Science Club of [University], the product has demanded many hours of hard work. The club is now trying to cash in on its development. To do so, they have decided to partner with the Marketing Club of [University]. You are a member of the [Marketing / Science] Club. Your joint team consists of members from both clubs. Each team member has a different area of expertise:

- Marketing:

- Pat-product pricing

- Jessie-customer needs

- Terry-product promotion

- Science:

- Robin-technology platform

- Chris - competitor analysis

- Marion - influence of technical experts in the field

- To get money to move forward with your development plans, you are meeting with a team of venture capitalists who are very busy and dislike meeting with large groups. They have asked you to conduct the majority of the meeting on your own. However, they are open to your bringing in a few people from either club to assist you.

We then directed participants to an on-line survey, which consisted of three sections. The first presented participants with three collaboration scenarios:

1. The Venture Capitalists ask, "In designing your product, you hopefully took into account the advantages and disadvantages of offering a more technologically sophisticated product. These might include the benefits of using new technology systems or higher quality materials and the costs (e.g., resources or time) associated with these enhancements. What will be the tradeoffs of upgrading to a new technology platform, and will we be able to increase prices enough to cover those tradeoffs?" 
To give the Venture Capitalists the best answer to this question, how many and which type of individuals would you want to consult with? Make your decision about who should accompany you based on your sense of the information needed and the smallest group that will accomplish the task of providing the best judgment. Keep in mind that more is not necessarily better and that having too many people in the room may alienate the venture capitalists who prefer small group meetings. Whom do you want to bring in to help you answer this question?

2. The Venture Capitalists ask, "We obviously do not want to invest in a product that consumers do not value or for which a perfectly good alternative already exists. How well does the product meet the needs of our key customers and to what extent are its features differentiated from competitive offerings?"

To give the Venture Capitalists the best answer to this question, how many and which type of individuals would you want to consult with? Make your decision about who should accompany you based on your sense of the information needed and the smallest group that will accomplish the task of providing the best judgment. Keep in mind that more is not necessarily better and that having too many people in the room may alienate the venture capitalists who prefer small group meetings. Whom do you want to bring in to help you answer this question?

3. The Venture Capitalists ask, "Before you can sell your product, it will be necessary to bring attention to it. There are many ways to do this but we seek the most effective method at the cheapest price. Are we better off spending more on product promotion or in trying to shape the opinions of technical thought leaders in the field?"

To give the Venture Capitalists the best answer to this question, how many and which type of individuals would you want to consult with? Make your decision about who should accompany you based on your sense of the information needed and the smallest group that will accomplish the task of providing the best judgment. Keep in mind that more is not necessarily better and that having too many people in the room may alienate the venture capitalists who prefer small group meetings. Whom do you want to bring in to help you answer this question?

The second section of the survey assessed participants' explicit collaborative self-concept (see details below). The final part of the survey posed a set of demographic questions.

Data for three participants were dropped from the analysis because of the manner in which they completed the Implicit Association Test - e.g., obviously rushing through the test or deliberately pressing the same key repeatedly. (The exclusion criteria were consistent with those used in the field study and aligned with past practice in IAT research.) The remaining 90 students had the following profile: mean age of 23.8, with a standard deviation of 8.0; 20 were 
graduate or extension school students (22\%); 40 were male (44\%); 40 were white $(44 \%) ; 26$ were economics majors (29\%); 28 were natural science majors $(31 \%) ; 24$ were psychology majors (27\%); and 12 were dual degree majors, did not report their major, or could not be neatly classified (13\%).

\section{Measures - Explicit Collaborative Self-Concept (ECS)}

We measured ECS using the following five items: (a) "What is your preferred way of working?" (ranging from 1, strongly prefer to work independently, to 7, strongly prefer to work collaboratively); (b) "Collaborating with others on a project increases the chances of success"; (c) "The most successful projects are ones where one can work independently of others"; (d) "Collaborating with others is necessary for career advancement"; and (e) "Working independently of others is the best way to get ahead in one's career." For items (b) through (e), respondents were presented with a 7 point scale to indicate the extent to which they disagreed or agreed with each statement. Reverse coding items (c) and (e), we created a composite measure of ECS (Cronbach's alpha of 0.73).

\section{Measures - Control Variables}

We used three dummy variables as controls. The first identified respondents who were graduate or extension school students. We reasoned that these subjects were more likely to have firsthand experience collaborating with others in organizational settings. In addition, we also controlled for respondents' gender and ethnicity (White or Non-White).

\section{Results}

Table A1 shows the descriptive statistics and correlations among the main variables of interest.

\section{- Table A1 about here -}

Table A2 reports the results of a negative binomial regression model, the response variable for which was the total number of collaborators chosen across all three scenarios. The 
coefficient for ICS was positive and statistically significant. The only other significant covariate was the dummy variable for advanced students (those in graduate or extension school).

- Table A2 about here -

Table A1. Descriptive Statistics and Correlation Matrix

\begin{tabular}{|c|c|c|c|c|c|c|c|c|c|}
\hline & Mean & $\begin{array}{c}\text { Standard } \\
\text { Deviation }\end{array}$ & (1) & (2) & (3) & (4) & (5) & (6) & (7) \\
\hline (1) ICS & -.71 & .43 & 1.00 & & & & & & \\
\hline $\begin{array}{l}\text { (2) ECS - } \\
\text { Composite } \\
\text { Measure }\end{array}$ & 7.8 & 4.8 & $\begin{array}{c}0.11 \\
(0.30)\end{array}$ & 1.00 & & & & & \\
\hline $\begin{array}{l}\text { (3) Type of } \\
\text { Student - Graduate } \\
\text { or Extension } \\
\text { School }\end{array}$ & .23 & .42 & $\begin{array}{c}0.03 \\
(0.81)\end{array}$ & $\begin{array}{c}-0.12 \\
(0.27)\end{array}$ & 1.00 & & & & \\
\hline (4) Gender - Male & .45 & .50 & $\begin{array}{l}-0.09 \\
(0.40) \\
\end{array}$ & $\begin{array}{l}-0.08 \\
(0.49) \\
\end{array}$ & $\begin{array}{l}-0.13 \\
(0.20) \\
\end{array}$ & 1.00 & & & \\
\hline $\begin{array}{l}\text { (5) Ethnicity - } \\
\text { White }\end{array}$ & .45 & .50 & $\begin{array}{c}0.08 \\
(0.47)\end{array}$ & $\begin{array}{l}-.30 \\
(0.00) \\
\end{array}$ & $\begin{array}{c}0.08 \\
(0.42)\end{array}$ & $\begin{array}{c}0.03 \\
(0.75)\end{array}$ & 1.00 & & \\
\hline $\begin{array}{l}\text { (6) Total Number } \\
\text { of Collaborators }\end{array}$ & 5.8 & 2.2 & $\begin{array}{c}0.20 \\
(0.06)\end{array}$ & $\begin{array}{c}0.02 \\
(0.86)\end{array}$ & $\begin{array}{c}0.18 \\
(0.09)\end{array}$ & $\begin{array}{c}0.05 \\
(0.63)\end{array}$ & $\begin{array}{l}-0.10 \\
(0.35)\end{array}$ & 1.00 & \\
\hline $\begin{array}{l}\text { (7) Total Number } \\
\text { of Out-Group } \\
\text { Collaborators }\end{array}$ & 3.4 & 1.3 & $\begin{array}{c}0.06 \\
(0.58)\end{array}$ & $\begin{array}{c}0.02 \\
(0.85)\end{array}$ & $\begin{array}{c}0.01 \\
(0.89)\end{array}$ & $\begin{array}{c}0.07 \\
(0.52)\end{array}$ & $\begin{array}{c}0.02 \\
(0.82)\end{array}$ & $\begin{array}{c}0.71 \\
(0.00)\end{array}$ & 1.00 \\
\hline
\end{tabular}

Note: $p$-values noted in parentheses. Type of Student $=1$ for Graduate or Extension School, 0 for Undergraduate or Unknown; Gender=1 for Male, 0 for Female; Ethnicity $=1$ for White, 0 for Other.

\section{Robustness Check}

We tested the robustness of these findings to the inclusion of two established individual difference constructs that have been associated with certain types of networks. The tertius iungens orientation, which has been validated in prior research (Obstfeld 2005), represents an individual's propensity to bring others together in collaboration. We used six items associated with this construct (Cronbach's alpha of 0.87): (a) "I introduce people to each other who might have a common strategic work interest"; (b) "I will try to describe an issue in a way that will 
appeal to a diverse set of interests"; (c) "I see opportunities for collaboration between people"; (d) "I point out the common ground shared by people who have different perspectives on an issue"; (e) "I introduce two people when I think they might benefit from becoming acquainted"; and (f) "I forge connections between different people dealing with a particular issue." In addition, we used a measure of collectivism-individualism, which has also been validated in prior research (Wagner and Moch 1986) and represents a person's orientation towards individuals versus collectives. We used four items associated with this construct (Cronbach's alpha of 0.59): (a) "Only those who depend on themselves get ahead in life"; (b) "One should live one's life independent of others as much as possible"; (c) "Working with a group is better than working alone"; and (d) "In society, people are born into extended families or clans who protect them in shared necessity for loyalty." The correlation between ICS and the measure of tertius iungens orientation was $0.141(\mathrm{p}=.183)$, while the correlation between ICS and collectivism-individualism was -.062 ( $\mathrm{p}=.565)$. Substitution of these measures for ECS in the model presented in Table A2 produced comparable results. In the model that included tertius iungens orientation, rather than ECS, the coefficient for ICS was positive and significant: .184 $(\mathrm{p}=.023)$. Similarly, in the model that included collectivism-individualism, rather than ECS, the coefficient for ICS was: $.180(\mathrm{p}=.025)$. Neither tertius iungens orientation nor collectivismindividualism was a significant covariate in these models. Thus, the results appeared to be robust to the inclusion of at least two established individual difference constructs. 
Table A2. Negative Binomial Regression:

Total Number of Collaborators Chosen

\begin{tabular}{|l|c|}
\hline \multicolumn{1}{|c|}{ Explanatory variables } & Coefficient \\
\hline Implicit Collaborative Self-Concept (ICS) & $\begin{array}{c}.172 * \\
(.082)\end{array}$ \\
\hline Explicit Collaborative Self-Concept (ECS) & -.000 \\
& $(.009)$ \\
\hline Type of Student - Graduate or Extension School & $.174 *$ \\
& $(.086)$ \\
\hline Gender - Male & .091 \\
& $(.079)$ \\
\hline Ethnicity - White & -.104 \\
& $(.083)$ \\
\hline Constant & $1.84 * * *$ \\
& $(.126)$ \\
\hline Number of Observations & 88 \\
\hline Prob $>$ chi 2 & .039 \\
\hline & p $<0.01, * * \mathrm{p}<0.05, * \mathrm{p}<0.10 ;$ Robust standard errors in parentheses
\end{tabular}




\section{Appendix B - Exponential Random Graph Models (ERGMs)}

ERGMs differ in important respects from typical regression analyses. The variables used in a typical regression analysis - both response and explanatory variables - are measured separately for each unit. In ERGMs, the response variable is typically the state of a dyad - e.g., the presence or absence of a tie between two people. Explanatory variables include attributes of the individuals (e.g., age), the dyads (e.g., whether or not two people are of the same gender), and the ties (e.g., the duration of measured tie). Some of the explanatory variables are functions of the ties themselves. These "network statistics" represent tie configurations that are believed to occur more or less often than expected by chance (Morris, Handcock, and Hunter 2008).

In their most general form, ERGMs allow the probability distribution of a network to depend on any set of network statistics:

$$
\operatorname{Pr}(\mathrm{X}=\mathrm{x})=\exp \left(\Sigma \theta_{\mathrm{k}} \mathrm{t}_{\mathrm{k}}(\mathrm{x})\right) / \mathrm{K}(\theta)
$$

Where:

$t_{k}(x) \quad$ is the value of the $k^{\text {th }}$ network statistic for network $x$ $\theta_{\mathrm{k}} \quad$ is the corresponding parameter

$\mathrm{K}(\theta)$ is a normalizing constant that ensures probabilities add to 1

The formula refers to the probability of observing a given network under a particular model. The network statistics indicate on which network properties the model conditions the probability distributions. There are two types of network processes reflected in network statistics: dyad dependent and dyad independent. The former include processes in which the state of one dyad depends on the state of others (e.g., the proposition that "the friend of a friend is my friend" suggests dependency between dyads), while the latter include processes in which there is no direct dependence among dyads (e.g., the proposition that "birds of a feather flock together" suggests attraction between socially similar people but no dependency between dyads). Unlike other statistical network modeling approaches, ERGMs can account for both types of 
dependency (Handcock, Hunter, Butts, Goodreau, and Morris 2008; O'Malley and Marsden 2008).

The general framework for constructing an exponential random graph model involves five steps: (1) each network tie is regarded as a random variable; (2) a dependence hypothesis (e.g., the general tendency toward reciprocity or influence of actor-level attributes on tie formation) is assumed and establishes contingencies among variables; (3) the dependence assumption implies a functional form of the model; (4) homogeneity constraints (e.g., that reciprocity parameters apply to the entire network, rather than to particular dyads) help simplify the model; and (5) parameters are estimated and interpreted (for a more detailed discussion of these steps, see Robins et al. 2007).

In estimating the exponential random graph models, we followed the procedure suggested by Snijders et al. (2006), and amended by Robins, Pattison, and Wang (2009), for the analysis of directed networks. Specifically, using the PNet software tool (Wang, Robins, and Pattison 2008), we first fitted a model that included eleven recommended network structural parameters, along with the actor- and dyad-level variables of interest. The network structural parameters included two Markov parameters ${ }^{14}$ - density, or the number of arcs (representing the baseline propensity to form ties); and reciprocity, or the number of bi-directional ties - and nine higherorder dependence terms - K-in-star (representing popularity with respect to indegree); K-out-star (representing popularity with respect to outdegree); AT-T, or path closure (representing structural holes); A2P-T, or multiple two-paths (representing multiple localized connectivity); AT-U, or activity closure (representing activity-based structural homophily); AT-D, or popularity closure (representing popularity-based structural homophily); AT-C, or cyclic closure

\footnotetext{
14 "Markov" dependence is any form of dependence containing configurations of ties in which pairs of network variables have at least one actor in common.
} 
(representing generalized exchange); A2P-U, or shared activity (representing activity-based structural equivalence); and A2P-D, or shared popularity (representing popularity-based structural equivalence). These higher-order dependence terms are depicted in Figure B1.

\section{- Figure B1 about here -}

Once we had run a large enough number of simulations to reach acceptable convergence statistics of $|\mathrm{t}|<.01$ ), we refined the model by dropping network structural parameters that were not statistically significant. Then, once we had a model with acceptable convergence statistics for the remaining covariates $(|t|<0.1)$, we ran goodness of fit simulations. Following Robins et al. (2009), we considered model fit acceptable when, in the goodness of fit simulations, $|\mathrm{t}|$ was less than 0.1 for all estimated parameters and less than 2.0 for all but one or two of the other parameters included in the simulation but not part of the model being tested.

As a robustness check, we also attempted to fit more parsimonious specifications of Models 5 and 6 (reported as Tables 4 and 5 in the main paper). In particular, we fitted models with only two network structural parameters (Arc and Reciprocity), two initiator covariates (Initiator's ICS and ECS), two target covariates (Target's ICS and ECS), and one dyadic covariate (Same Location) as controls. These results are reported in Tables B1 and B2. Although these models produced similar results for the variables as interest as Models 5 and 6 , they did not meet the criteria noted above for acceptable goodness-of-fit. Hence, we report only the results of Models 5 and 6, which did meet those criteria, in the main body.

\section{- Table B1 about here -}

\section{- Table B2 about here -}


Figure B1 - Dependence Terms in Exponential Random Graph Models

A. Dyadic Parameters:

- Density (Number of arcs, or the baseline propensity to form ties)

- Reciprocity (Number of bidirectional ties, or the propensity for reciprocation)

B. Degree-Based Parameters:

- K-in-star (Popularity with respect to indegree)

- K-out-star (Popularity with respect to outdegree)

C. Multiple Connectivity:

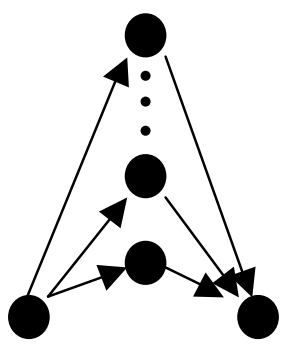

Multiple Two-Paths (A2P-T)

D. Closure:

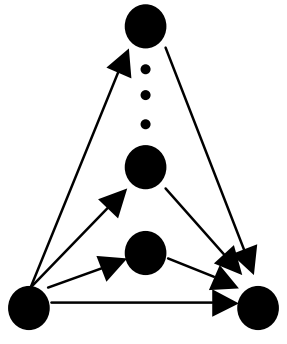

Path Closure (AT-T)

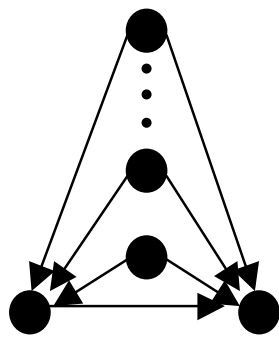

Popularity Closure (AT-D)

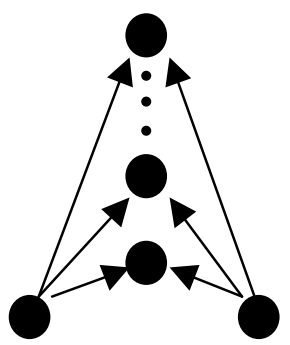

Shared Activity (A2P-U)

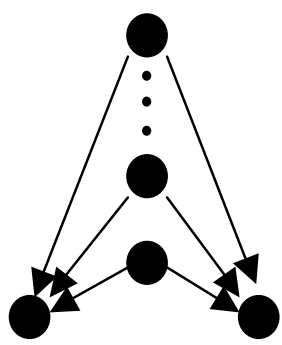

Shared Popularity (A2P-D)

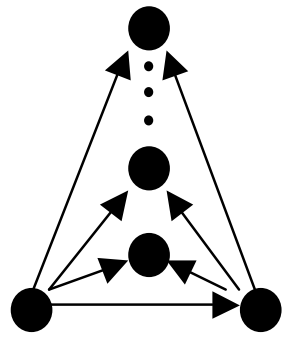

Activity Closure (AT-U)

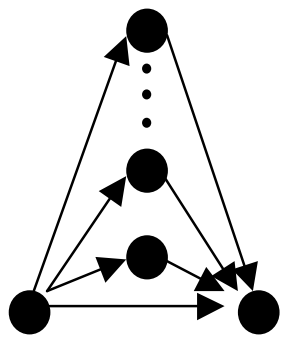

Cyclic Closure (AT-C)

Source: Adapted from Robins, Pattison, and Wang (2009) 
Table B1. Alternative Specification of Model 5 - Horizontal Boundary Spanning

Conditional Log-Odds of Directed Tie Between Dyadic Pair Alternative Specification of Model 5 (Exponential Random Graph Model)

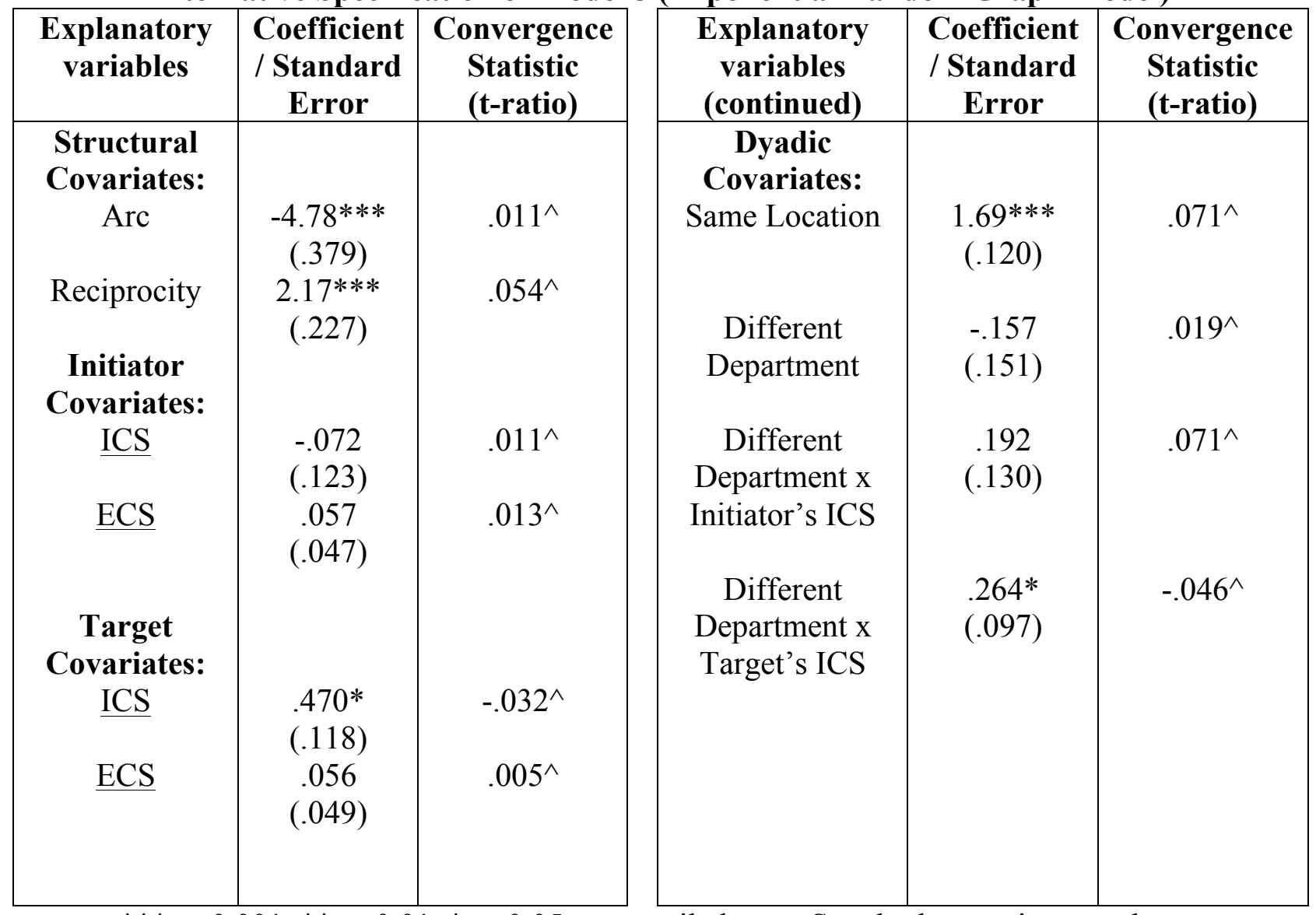

*** $\mathrm{p}<0.001,{ }^{* *} \mathrm{p}<0.01,{ }^{*} \mathrm{p}<0.05-$ two-tailed tests; Standard errors in parentheses

$\wedge|t|$ statistic below recommended threshold of 0.10 for model convergence 
Table B2. Alternative Specification of Model 6 - Vertical Boundary Spanning

Conditional Log-Odds of Directed Tie Between Dyadic Pair Alternative Specification of Model 6 (Exponential Random Graph Model)

\begin{tabular}{|c|c|c|c|c|c|}
\hline $\begin{array}{c}\text { Explanatory } \\
\text { variables }\end{array}$ & $\begin{array}{l}\text { Coefficient } \\
\text { / Standard } \\
\text { Error }\end{array}$ & $\begin{array}{c}\text { Convergence } \\
\text { Statistic } \\
\text { (t-ratio) }\end{array}$ & $\begin{array}{l}\text { Explanatory } \\
\text { variables } \\
\text { (continued) }\end{array}$ & $\begin{array}{l}\text { Coefficient } \\
\text { / Standard } \\
\text { Error }\end{array}$ & $\begin{array}{c}\text { Convergence } \\
\text { Statistic } \\
\text { (t-ratio) }\end{array}$ \\
\hline $\begin{array}{c}\text { Structural } \\
\text { Covariates: } \\
\text { Arc }\end{array}$ & $\begin{array}{c}-4.83 * * * \\
(.381)\end{array}$ & $.049^{\wedge}$ & $\begin{array}{c}\text { Dyadic } \\
\text { Covariates: } \\
\text { Same Location }\end{array}$ & $\begin{array}{l}1.700 * * * \\
(.118)\end{array}$ & $.006^{\wedge}$ \\
\hline $\begin{array}{l}\text { Reciprocity } \\
\text { Initiator }\end{array}$ & $\begin{array}{c}2.18 * * * \\
(.227)\end{array}$ & $-.017^{\wedge}$ & Different Grade & $\begin{array}{l}-.027 \\
(.125)\end{array}$ & $-.008^{\wedge}$ \\
\hline $\begin{array}{c}\text { Covariates: } \\
\text { ICS }\end{array}$ & $\begin{array}{l}-.092 \\
(.117)\end{array}$ & $-.026^{\wedge}$ & $\underset{\mathrm{x}}{\text { Different Grade }}$ & $\begin{array}{l}.258^{*} \\
(.121)\end{array}$ & $-.005^{\wedge}$ \\
\hline$\underline{\mathrm{ECS}}$ & $\begin{array}{l}.049 \\
(.046)\end{array}$ & $.060^{\wedge}$ & Initiator's ICS & & \\
\hline Target & & & $\begin{array}{c}\text { Different Grade } \\
\text { x Target's ICS }\end{array}$ & $\begin{array}{l}.332^{*} \\
(.117)\end{array}$ & $-.001^{\wedge}$ \\
\hline ICS & $\begin{array}{l}.320^{*} \\
(.142)\end{array}$ & $-.072^{\wedge}$ & & & \\
\hline$\underline{\mathrm{ECS}}$ & $\begin{array}{l}.056 \\
(.049)\end{array}$ & $.041^{\wedge}$ & & & \\
\hline
\end{tabular}

$* * * \mathrm{p}<0.001, * * \mathrm{p}<0.01, * \mathrm{p}<0.05-$ two-tailed tests; Standard errors in parentheses

$\wedge|t|$ statistic below recommended threshold of 0.10 for model convergence 
Appendix C - Scatterplot Matrix

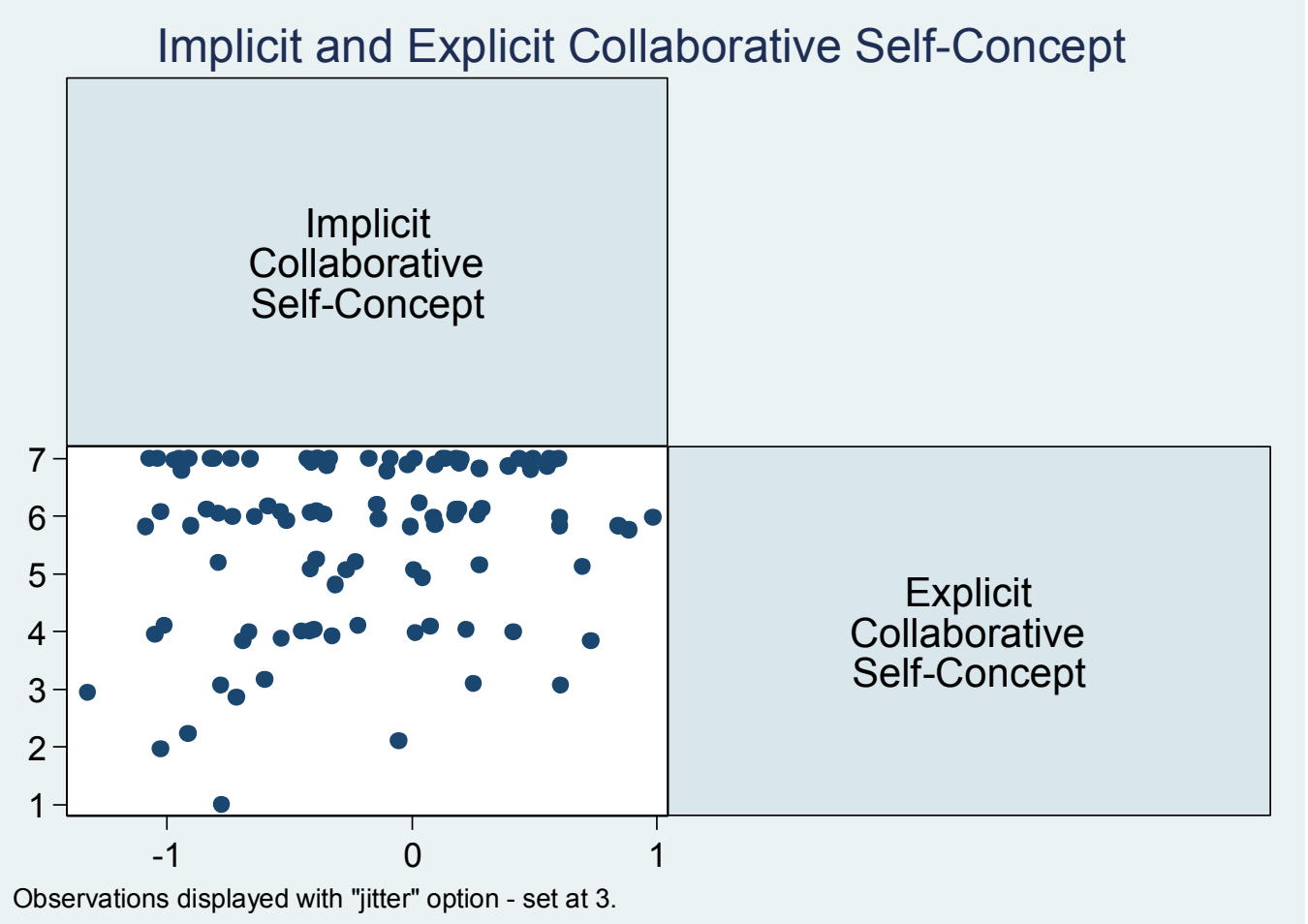


References

2006. "Inquisit 2.0.60616." Seattle, WA: Millisecond Software.

Arkes, Hal R. and Philip E. Tetlock. 2004. "Attributions of Implicit Prejudice, or 'Would Jesse Jackson 'Fail' the Implicit Association Test?'" Psychological Inquiry 15:257-278.

Astley, W. Graham and Paramjit S. Sachdeva. 1984. "Structural Sources of Intraorganizational Power: A Theoretical Synthesis." The Academy of Management Review 9:104-113.

Banaji, Mahzarin R. and Anthony G. Greenwald. 1994. "Implicit Stereotyping and Prejudice." in The Psychology of Prejudice, vol. The Ontario Symposium: Volume 7, edited by M. P. Zanna and J. M. Olson. Hillsdale, NJ: Lawrence Erlbaum Associates, Inc.

Banaji, Mahzarin R., Brian A. Nosek, and Anthony G. Greenwald. 2004. "No Place for Nostalgia in Science: A Response to Arkes and Tetlock." Psychological Inquiry 15:279-310.

Bargh, John A., Peter M. Gollwitzer, Annette Lee-Chai, Kimberly Barndollar, and Roman Trotschel. 2001. "The automated will: nonconscious activation and pursuit of behavioral goals." Journal of Personality and Social Psychology 81:1014-1027.

Bechky, Beth A. 2003. "Sharing meaning across occupational communities: the transformation of understanding on a production floor." Organization Science 14:312-330.

Blau, Peter M. 1970. "A Formal Theory of Differentiation in Organizations." American Sociological Review 35:201-218.

Bourdieu, Pierre. 1986. Distinction: A Social Critique of the Judgment of Taste. Translated by R. Nice. London: Routledge and Kegan Paul.

Brosig, Jeannette. 2002. "Identifying cooperative behavior: some experimental results in a prisoner's dilemma game." Journal of Economic Behavior \& Organization 47:275-290.

Burke, Peter J. 2006. "Identity Change." Social Psychology Quarterly 69:81-96.

Burke, Peter J. and Jan E. Stets. 2009. Identity Theory. New York, NY: Oxford University Press.

Burke, Peter J. and Judy C. Tully. 1977. "The Measurement of Role Identity." Social Forces 55:881-897.

Burt, Ronald. 1992. Structural Holes: The Social Structure of Competition. Cambridge, MA: Harvard University Press.

Burt, Ronald S., Joseph E. Jannotta, Jr., and James T. Mahoney. 1998. "Personality correlates of structural holes." Social Networks 20:63-87.

Callero, Peter L. 1985. "Role-Identity Salience." Social Psychology Quarterly 48:203-215.

-. 1992. "The Meaning of Self-in-Role: A Modified Measure of Role-Identity." Social Forces 71:485-501.

Carley, Kathleen M. 1991. "Growing Up: The Development and Acquisition of Social Knowledge." in The Self-Society Dynamic: Cognition, Emotion and Action, edited by J. A. Howard and P. L. Callero. Cambridge, UK: Cambridge University Press.

Casciaro, Tiziana. 1998. "Seeing things clearly: social structure, personality, and accuracy in social network perception." Social Networks 20:331-351.

Cast, Alicia D., Jan E. Stets, and Peter J. Burke. 1999. "Does the Self Conform to the Views of Others?" Social Psychology Quarterly 62:68-82.

Cerulo, Karen A. 1988. Deciphering Violence: The Cognitive Structure of Right and Wrong. New York: Routledge.

-. 2002. Culture in Mind: Toward a Sociology of Culture and Cognition New York: Routledge.

-. 2010. "Mining the Intersections of Culture and Cognitive Science." Poetics 38:115-132.

Coleman, James S. 1988. "Social Capital in the Creation of Human Capital." American Journal of Sociology 94:S95 -

Cooley, Charles H. 1902. Human nature and the social order. New York: Scribners. 
Danna Lynch, Karen. 2007. "Modeling Role Enactment: Linking Role Theory and Social Cognition." Journal for the Theory of Social Behaviour 37:379-399.

DePaulo, Bella M. 1992. "Nonverbal behavior and self-presentation." Psychological Bulletin 111:203-243. DiMaggio, Paul. 1997. "Culture and Cognition." Annual Review of Sociology 23:263-288.

-. 2002. "Why Cognitive (and Cultural) Sociology Needs Cognitive Psychology." Pp. 274-281 in Culture in Mind: Toward a Sociology of Culture and Cognition, edited by K. A. Cerulo. New York: Routledge.

Dougherty, Deborah. 1992. "Interpretive Barriers to Successful Product Innovation in Large Firms." Organization Science 3:179-202.

Evans, Jonathan St. B. T. 2008. "Dual-processing accounts of reasoning, judgment, and social cognition." Annual Review of Psychology 59:255-278.

Feld, Scott L. and William C. Carter. 2002. "Detecting Measurement Bias in Respondent Reports of Personal Networks." Social Networks 24:365-383.

Felson, Richard B. 1985. "Reflected Appraisal and the Development of the Self." Social Psychology Quarterly 48:71-78.

Felson, Richard B. and Mark D. Reed. 1986. "Reference Groups and Self-Appraisals of Academic Ability and Performance." Social Psychology Quarterly 49:103-109.

Fiske, Susan T. and Shelley Taylor. 2007. Social Cognition: From Brains to Culture. New York: McGrawHill.

Fleming, Lee and David M. Waguespack. 2007. "Brokerage, Boundary Spanning, and Leadership in Open Innovation Communities." Organization Science.

Fombrun, Charles. 1983. "Attributions of power across a social network." Human Relations 36:493-508.

Frank, Robert H., Thomas Gilovich, and Dennis T. Regan. 1993. "The evolution of one-shot cooperation: An experiment." Ethology and Sociobiology 14:247-256.

Gecas, Viktor. 1982. "The Self-Concept." Annual Review of Sociology 8:1-33.

-. 2000. "Value-Identities, Self-Motives, and Social Movements." in Self, Identity, and Social Movements, edited by S. Stryker, T. J. Owens, and R. W. White. Minneapolis: University of Minnesota Press.

Goffman, Erving. 1959. The Presentation of Self in Everyday Life. Garden City, NY: Doubleday.

Greenwald, Anthony G. and Mahzarin R. Banaji. 1995. "Implicit Social Cognition: Attitudes, Self-Esteem, and Stereotypes." Psychological Review 102:4-27.

Greenwald, Anthony G., Debbie E. McGhee, and Jordan L. K. Schwartz. 1998. "Measuring individual differences in implicit cognition: The implicit association test." Journal of Personality and Social Psychology 74:1464-1480.

Greenwald, Anthony G., T. Andrew Poehlman, Eric Uhlmann, and Mahzarin R. Banaji. 2009. "Understanding and using the Implicit Association Test: III. Meta-analysis of predictive validity." Journal of Personality and Social Psychology 97:17-41.

Handcock, Mark S., David R. Hunter, Carter T. Butts, Steven M. Goodreau, and Martina Morris. 2008. "statnet: Software Tools for the Representation, Visualization, Analysis and Simulation of Network Data." Journal of Statistical Software 24:1-11.

Hitlin, Steven. 2003. "Values as the Core of Personal Identity: Drawing Links Between Two Theories of Self." Social Psychology Quarterly 66:118-137.

Hogg, Michael A. and Dominic Abrams. 2003. "Intergroup behavior and social identity." in The Sage Handbook of Social Psychology, edited by M. A. Hogg and D. Abrams. Thousand Oaks, CA: Sage.

Hogg, Michael A. and Cecilia L. Ridgeway. 2003. "Social Identity: Sociological and Social Psychological Perspectives." Social Psychology Quarterly 66:97-100.

Ibarra, Herminia. 1995. "Race, opportunity, and diversity of social circles in managerial networks." Academy of Management Journal 38:673-703. 
Ichiyama, Michael A. 1993. "The Reflected Appraisal Process in Small-Group Interaction." Social Psychology Quarterly 56:87-99.

Jost, John T., Laurie A. Rudman, Irene V. Blair, Dana R. Carney, Nilanjana Dasgupta, Jack Glaser, and Curtis D. Hardin. 2009. "The Existence of Implicit Bias is Beyond Reasonable Doubt: A Refutation of Ideological and Methodological Objections and Executive Summary of Ten Studies that No Manager Should Ignore." Research in Organizational Behavior 29:39-69.

Karpinski, A. and J. L. Hilton. 2001. "Social Influence Effects on Automatic Racial Prejudice." Journal of Personality and Social Psychology 81:842-855.

Kilduff, Martin and David Krackhardt. 1994. "Bringing the Individual Back in: A Structural Analysis of the Internal Market for Reputation in Organizations." The Academy of Management Journal 37:87108.

Krackhardt, D. 1987. "Cognitive Social Structures." Social Networks 9:109-134.

-. 1990. "Assessing the Political Landscape - Structure, Cognition, and Power in Organizations." Administrative Science Quarterly 35:342-369.

Krackhardt, David and Martin Kilduff. 1999. "Whether close or far: Social distance effects on perceived balance in friendship networks." Journal of Personality \& Social Psychology 76:770-782.

Lane, Kristin A., Mahzarin R. Banaji, Brian A. Nosek, and Anthony G. Greenwald. 2007. "Understanding and Using the Implicit Association Test: IV - What We Know (So Far) About the Method." Pp. 59-102 in Implicit Measures of Attitudes, edited by B. Wittenbrink and N. Schwarz. New York: Guilford Press.

Lawrence, Paul R. and Jay W. Lorsch. 1967. "Differentiation and Integration in Complex Organizations." Administrative Science Quarterly 12:1-47.

Lazarsfeld, Paul F. and Robert K. Merton. 1954. "Friendship as a Social Process: A Substantive and Methodological Analysis." in Freedom and Control in Modern Society, edited by M. Berger. New York: Van Nostrand.

Lieberman, Matthew D., Johanna M. Jarcho, and Ajay B. Satpute. 2004. "Evidence-Based and IntuitionBased Self-Knowledge: An fMRI Study." Journal of Personality and Social Psychology 87:421-435.

Lizardo, Omar. 2006. "How Cultural Tastes Shape Personal Networks." American Sociological Review 71:778-807.

Lowery, Brian S., Curtis D. Hardin, and Stacey Sinclair. 2001. "Social influence effects on automatic racial prejudice." Journal of Personality and Social Psychology 81:842-855.

Markus, Hazel. 1977. "Self-schemata and processing information about the self." Journal of Personality and Social Psychology 35:63-78.

Markus, Hazel and Ziva Kunda. 1986. "Stability and malleability of the self-concept." Journal of Personality and Social Psychology 51:858-866.

Martin, John Levi. 2000. "The Relation of Aggregate Statistics on Beliefs to Culture and Cognition." Poetics 28:5-20.

Martin, John Levi and Matt Desmond. 2010. "Political Position and Social Knowledge." Sociological Forum 25:1-26.

McCall, George J. and J.L. Simmons. 1978. Identities and Interactions: An Examination of Human Associations in Everyday Life. New York, NY: Free Press.

McLean, Paul D. 1998. "A Frame Analysis of Favor Seeking in the Renaissance: Agency, Networks, and Political Culture." American Journal of Sociology 104:51-91.

McPherson, Miller, Lynn Smith-Lovin, and James M. Cook. 2001. "Birds of a feather: Homophily in social networks." Annual Review of Sociology 27:415-444.

Mehra, Ajay, Martin Kilduff, and Daniel J. Brass. 2001. "The social networks of high and low selfmonitors: Implications for workplace performance." Administrative Science Quarterly 46:121146. 
Mitchell, Jason P., Brian A. Nosek, and Mahzarin R. Banaji. 2003. "Contextual Variations in Implicit Evaluation." Journal of Experimental Psychology: General 132:455-469.

Miyamoto, S. Frank and Sanford M. Dornbush. 1956. "A Test of Interactionist Hypotheses of SelfConception "The American Journal of Sociology 61:399-403.

Mohr, John W. 1998. "Measuring Meaning Structures." Annual Review of Sociology 24:345.

Morgan, David L. and Michael L. Schwalbe. 1990. "Mind and Self in Society: Linking Social Structure and Social Cognition." Social Psychology Quarterly 53:148-164.

Morris, Martina, Mark S. Handcock, and David R. Hunter. 2008. "Specication of Exponential-Family Random Graph Models: Terms and Computational Aspects." Journal of Statistical Software 24:124.

Nisbett, Richard E. and Timothy DeCamp Wilson. 1977. "Telling More Than We Can Know: Verbal Reports on Mental Processes." Psychological Review 84:231-259.

O'Malley, James A. and Peter V. Marsden. 2008. "The analysis of social networks." Health Services and Outcomes Research Methodology 8:222-269.

Obstfeld, D. 2005. "Social networks, the Tertius lungens and orientation involvement in innovation." Administrative Science Quarterly 50:100-130.

Pachucki, Mark A. and Ronald L. Breiger. 2010. "Cultural Holes: Beyond Relationality in Social Networks and Culture." Annual Review of Sociology 36:205-224.

Quillian, Lincoln. 2006. "New Approaches to Understanding Racial Prejudice and Discrimination." Annual Review of Sociology 32:299-328.

Reynolds, Larry T. and Nancy J. Herman-Kinney. 2003. Handbook of Symbolic Interactionism. Walnut Creek, CA: AltaMira Press.

Robins, Garry, Pip Pattison, Yuval Kalish, and Dean Lusher. 2007. "An introduction to exponential random graph ( $\left.p^{*}\right)$ models for social networks." Social Networks 29:173-191.

Robins, Garry, Pip Pattison, and Peng Wang. 2009. "Closure, connectivity and degrees: new specifications for exponential random graph $\left(p^{*}\right)$ models for directed social networks." Social Networks 31:105-117.

Rosenberg, Morris. 1979. Conceiving the Self. New York: Basic Books.

Schein, Edgar H. 1985. Organizational Culture and Leadership. San Francisco: Jossey-Bass.

Schnabel, Konrad, Jens B. Asendorpf, and A. G. Greenwald. 2007. "Using Implicit Association Tests for the Assessment of Implicit Personality Self-Concept." in Handbook of Personality Theory and Testing, edited by G. J. Boyle, G. Matthews, and H. Saklofske. London: Sage.

Schwarz, Norbert. 1998. "Warmer and More Social: Recent Developments in Cognitive Social Psychology." Annual Review of Sociology 24:239-264.

Shah, James. 2003. "Automatic for the People: How Representations of Significant Others Implicitly Affect Goal Pursuit." Journal of Personality and Social Psychology 84:661-681.

Snijders, Tom A. B., Philippa E. Pattison, Garry L. Robins, and Mark S. Handcock. 2006. "New Specifications for Exponential Random Graph Models." Sociological Methodology 36:99-153.

Steglich, Christian, Tom A. B. Snijders, and Patrick West. 2006. "Applying SIENA: An Illustrative Analysis of the Coevolution of Adolescents' Friendship Networks, Taste in Music, and Alcohol Consumption." Methodology: European Journal of Research Methods for the Behavioral and Social Sciences 2:48-56.

Stryker, Sheldon. 1987. "The revitalization of symbolic interactionism." Social Psychology Quarterly 50:83-94.

Stryker, Sheldon and Peter J. Burke. 2000. "The Past, Present, and Future of an Identity Theory." Social Psychology Quarterly 63:284-297.

Swidler, Ann. 1986. "Culture in Action: Symbols and Strategies." American Sociological Review 51:273286. 
-. 2001. Talk of Love. Chicago, IL: University of Chicago Press.

Tetlock, Philip E. and Gregory Mitchell. 2009. "Implicit Bias and Accountability Systems: What Must Organizations Do to Prevent Discrimination?" Research in Organizational Behavior 29:3-38.

Thomas, Kenneth W. and Ralph H. Kilmann. 1975. "The Social Desirability Variable in Organizational Research: An Alternative Explanation for Reported Findings." The Academy of Management Journal 18:741-752.

Thompson, James D. 1967. Organizations in Action: Social Science Bases of Administrative Theory. New York: McGraw-Hill.

Totterdell, Peter, David Holman, and Amy Hukin. 2008. "Social Networkers: Measuring and Examining Individual Differences in Propensity to Connect with Others." Social Networks 2008:283-296.

Tsai, Wenpin. 2002. "Social Structure of "Coopetition" within a Multiunit Organization: Coordination, Competition, and Intraorganizational Knowledge Sharing." Organization Science 13:179-190.

Tsai, Wenpin and Sumantra Ghoshal. 1998. "Social Capital and Value Creation: The Role of Intrafirm Networks." The Academy of Management Journal 41:464-476.

Vaisey, Stephen. 2009. "Motivation and Justification: A Dual-Process Model of Culture in Action." American Journal of Sociology 114:1675-715.

Vaisey, Stephen and Omar Lizardo. 2010. "Can Cultural Worldviews Influence Network Composition." Social Forces 88:1595-1618.

Wagner, John A. 1995. "Studies of Individualism-Collectivism: Effects of Cooperation in Groups." The Academy of Management Journal 38:152-172.

Wagner, John A and M.K. Moch. 1986. "Individualism-collectivism: concept and measure." Group and Organization Studies 11:280-303.

Walker, Gordon. 1985. "Network Position and Cognition in a Computer Software Firm." Administrative Science Quarterly 30:103-130.

Walton, Richard E. and John M. Dutton. 1969. "The Management of Interdepartmental Conflict: A Model and Review." Administrative Science Quarterly 14:73-84.

Wang, Peng, Garry Robins, and Philippa Pattison. 2008. "PNet: Program for the Simulation and Estimation of $\mathrm{P}^{*}$ Exponential Random Graph Models." Department of Psychology, University of Melbourne.

Wittenbrink, Bernd and Norbert Schwarz. 2007. "Introduction." in Implicit measures of attitudes, edited by B. Wittenbrink and N. Schwarz. New York: Guilford Press.

Yeung, King-To and John Levi Martin. 2003. "The Looking Glass Self: An Empirical Test and Elaboration." Social Forces 81:843-881.

Zemljic, Barbara and Valentina Hlebec. 2005. "Reliability of measures of centrality and prominence." Social Networks 27:73-88. 
Tables and Figures 
Table 1: Descriptive Statistics and Correlation Matrix

\begin{tabular}{|c|c|c|c|c|c|c|c|c|c|c|c|}
\hline & Mean & $\begin{array}{l}\text { Std. } \\
\text { Dev. }\end{array}$ & (1) & (2) & (3) & (4) & (5) & (6) & (7) & (8) & (9) \\
\hline $\begin{array}{l}\text { (1) Implicit Collaborative Self- } \\
\text { Concept }\end{array}$ & -0.21 & 0.53 & 1.000 & & & & & & & & \\
\hline $\begin{array}{l}\text { (2) Explicit Collaborative Self- } \\
\text { Concept }\end{array}$ & 5.75 & 1.37 & $\begin{array}{r}0.159 \\
(0.119) \\
\end{array}$ & 1.000 & & & & & & & \\
\hline (3) Gender - Male & 0.56 & 0.50 & $\begin{array}{c}0.136 \\
(0.183)\end{array}$ & $\begin{array}{c}0.045 \\
(0.652)\end{array}$ & 1.000 & & & & & & \\
\hline (4) Ethnicity - White & 0.83 & 0.37 & $\begin{array}{c}0.044 \\
(0.669)\end{array}$ & $\begin{array}{c}0.073 \\
(0.466)\end{array}$ & $\begin{array}{l}-0.079 \\
(0.427)\end{array}$ & 1.000 & & & & & \\
\hline (5) Education - MD / PhD & 0.47 & 0.50 & $\begin{array}{c}0.167 \\
(0.100) \\
\end{array}$ & $\begin{array}{c}0.114 \\
(0.255) \\
\end{array}$ & $\begin{array}{c}0.165 \\
(0.097) \\
\end{array}$ & $\begin{array}{l}-0.105 \\
(0.292) \\
\end{array}$ & 1.000 & & & & \\
\hline (6) Tenure (Years) & 4.63 & 2.80 & $\begin{array}{c}0.154 \\
(0.131)\end{array}$ & $\begin{array}{c}0.117 \\
(0.245)\end{array}$ & $\begin{array}{c}0.152 \\
(0.128)\end{array}$ & $\begin{array}{c}0.147 \\
(0.140)\end{array}$ & $\begin{array}{c}0.149 \\
(0.135) \\
\end{array}$ & 1.000 & & & \\
\hline (7) Salary Grade & 80.98 & 16.7 & $\begin{array}{c}0.140 \\
(0.170)\end{array}$ & $\begin{array}{c}0.188 \\
(0.060)\end{array}$ & $\begin{array}{c}0.224 \\
(0.024)\end{array}$ & $\begin{array}{c}0.121 \\
(0.227)\end{array}$ & $\begin{array}{c}0.368 \\
(0.000)\end{array}$ & $\begin{array}{c}0.170 \\
(0.088)\end{array}$ & 1.000 & & \\
\hline (8) Function - R\&D & 0.43 & 0.50 & $\begin{array}{c}0.101 \\
(0.324)\end{array}$ & $\begin{array}{c}0.188 \\
(0.059)\end{array}$ & $\begin{array}{c}0.295 \\
(0.003)\end{array}$ & $\begin{array}{c}0.071 \\
(0.479)\end{array}$ & $\begin{array}{c}0.448 \\
(0.000)\end{array}$ & $\begin{array}{c}0.285 \\
(0.004)\end{array}$ & $\begin{array}{c}0.304 \\
(0.002)\end{array}$ & 1.000 & \\
\hline (9) Task Interdependence & 2.59 & 1.14 & $\begin{array}{c}0.174 \\
(0.088) \\
\end{array}$ & $\begin{array}{c}0.101 \\
(0.315) \\
\end{array}$ & $\begin{array}{l}-0.050 \\
(0.617) \\
\end{array}$ & $\begin{array}{l}-0.091 \\
(0.366) \\
\end{array}$ & $\begin{array}{c}0.113 \\
(0.260) \\
\end{array}$ & $\begin{array}{l}-0.100 \\
(0.318) \\
\end{array}$ & $\begin{array}{r}0.278 \\
(0.005) \\
\end{array}$ & $\begin{array}{l}-0.125 \\
(0.211) \\
\end{array}$ & 1.000 \\
\hline $\begin{array}{l}\text { (10) Colleagues Enlisted in } \\
\text { Collaboration }\end{array}$ & 10.05 & 11.26 & $\begin{array}{c}0.122 \\
(0.232) \\
\end{array}$ & $\begin{array}{c}0.065 \\
(0.520) \\
\end{array}$ & $\begin{array}{c}0.027 \\
(0.789) \\
\end{array}$ & $\begin{array}{c}0.061 \\
(0.545) \\
\end{array}$ & $\begin{array}{l}-0.104 \\
(0.298) \\
\end{array}$ & $\begin{array}{l}-0.080 \\
(0.424)\end{array}$ & $\begin{array}{c}0.049 \\
(0.625)\end{array}$ & $\begin{array}{l}-0.041 \\
(0.683)\end{array}$ & $\begin{array}{l}-0.128 \\
(0.203)\end{array}$ \\
\hline $\begin{array}{l}\text { (11) Colleagues Enlisted in } \\
\text { Collaboration - Different } \\
\text { Departments }\end{array}$ & 3.50 & 5.34 & $\begin{array}{c}0.257 \\
(0.011)\end{array}$ & $\begin{array}{c}0.082 \\
(0.417)\end{array}$ & $\begin{array}{c}0.091 \\
(0.363)\end{array}$ & $\begin{array}{c}0.042 \\
(0.675)\end{array}$ & $\begin{array}{l}-0.081 \\
(0.417)\end{array}$ & $\begin{array}{l}-0.007 \\
(0.947)\end{array}$ & $\begin{array}{c}0.103 \\
(0.302)\end{array}$ & $\begin{array}{l}-0.086 \\
(0.392)\end{array}$ & $\begin{array}{c}0.056 \\
(0.576)\end{array}$ \\
\hline $\begin{array}{l}\text { (12) Colleagues Enlisted in } \\
\text { Collaboration - Different } \\
\text { Salary Grade }\end{array}$ & 4.33 & 7.14 & $\begin{array}{c}0.069 \\
(0.499)\end{array}$ & $\begin{array}{l}-0.012 \\
(0.907)\end{array}$ & $\begin{array}{l}-0.069 \\
(0.488)\end{array}$ & $\begin{array}{l}-0.001 \\
(0.990)\end{array}$ & $\begin{array}{l}-0.135 \\
(0.175)\end{array}$ & $\begin{array}{l}-0.080 \\
(0.425)\end{array}$ & $\begin{array}{l}-0.075 \\
(0.454)\end{array}$ & $\begin{array}{l}-0.291 \\
(0.003)\end{array}$ & $\begin{array}{l}-0.127 \\
(0.207)\end{array}$ \\
\hline $\begin{array}{l}\text { (13) Colleagues Supported in } \\
\text { Collaboration }\end{array}$ & 3.48 & 3.01 & $\begin{array}{c}0.299 \\
(0.002)\end{array}$ & $\begin{array}{c}0.056 \\
(0.554)\end{array}$ & $\begin{array}{c}0.056 \\
(0.104)\end{array}$ & $\begin{array}{c}0.146 \\
(0.000)\end{array}$ & $\begin{array}{c}0.217 \\
(0.000)\end{array}$ & $\begin{array}{c}0.106 \\
(0.003)\end{array}$ & $\begin{array}{c}0.518 \\
(0.000)\end{array}$ & $\begin{array}{c}-0.089 \\
(0.010)\end{array}$ & $\begin{array}{c}0.173 \\
(0.066)\end{array}$ \\
\hline
\end{tabular}




\begin{tabular}{|c|c|c|c|c|c|c|c|c|c|c|c|}
\hline $\begin{array}{l}\text { (14) Colleagues Supported in } \\
\text { Collaboration - Different } \\
\text { Departments }\end{array}$ & 1.81 & 2.44 & $\begin{array}{c}0.237 \\
(0.013)\end{array}$ & $\begin{array}{l}-0.006 \\
(0.947)\end{array}$ & $\begin{array}{c}0.058 \\
(0.093)\end{array}$ & $\begin{array}{c}0.159 \\
(0.000)\end{array}$ & $\begin{array}{c}0.200 \\
(0.000)\end{array}$ & $\begin{array}{c}0.133 \\
(0.000)\end{array}$ & $\begin{array}{c}0.499 \\
(0.000)\end{array}$ & $\begin{array}{c}0.069 \\
(0.045)\end{array}$ & $\begin{array}{c}0.195 \\
(0.038)\end{array}$ \\
\hline $\begin{array}{l}\text { (15) Colleagues Supported in } \\
\text { Collaboration - Different } \\
\text { Salary Grade }\end{array}$ & 1.47 & 1.93 & $\begin{array}{c}0.244 \\
(0.010)\end{array}$ & $\begin{array}{c}0.087 \\
(0.361)\end{array}$ & $\begin{array}{c}0.047 \\
(0.176)\end{array}$ & $\begin{array}{c}0.137 \\
(0.000)\end{array}$ & $\begin{array}{c}0.120 \\
(0.001)\end{array}$ & $\begin{array}{c}0.081 \\
(0.021)\end{array}$ & $\begin{array}{c}0.365 \\
(0.000)\end{array}$ & $\begin{array}{c}-0.210 \\
(0.000)\end{array}$ & $\begin{array}{c}0.083 \\
(0.382)\end{array}$ \\
\hline
\end{tabular}

Note: $p$ values in parentheses. 
Table 2: Negative Binomial Regression Analyses - Colleagues Enlisted in Collaboration

\begin{tabular}{|c|c|c|}
\hline & $\begin{array}{c}\text { Model 1: Colleagues Enlisted } \\
\text { in Collaboration - Different } \\
\text { Departments }\end{array}$ & $\begin{array}{c}\text { Model 2: Colleagues Enlisted } \\
\text { in Collaboration - Different } \\
\text { Salary Grade }\end{array}$ \\
\hline Implicit Collaborative Self- & $0.577^{*}$ & 0.207 \\
Concept & $(0.230)$ & $(0.235)$ \\
\hline Explicit Collaborative Self- & 0.060 & 0.078 \\
Concept & $(0.084)$ & $(0.089)$ \\
\hline Gender - Male & 0.048 & -0.035 \\
& $(0.258)$ & $(0.269)$ \\
\hline Ethnicity - White & $0.676^{*}$ & 0.248 \\
& $(0.325)$ & $(0.249)$ \\
\hline Education - MD / PhD & -0.025 & 0.584 \\
& $(0.282)$ & $(0.359)$ \\
\hline Log Tenure & 0.110 & 0.150 \\
& $(0.183)$ & $(0.175)$ \\
\hline Log Salary Grade & 1.010 & 0.702 \\
& $(0.680)$ & $(0.564)$ \\
\hline Function - R\&D & -0.435 & $-1.884^{* * *}$ \\
& $(0.295)$ & $(0.411)$ \\
\hline Task Interdependence & -0.110 & $-0.372^{* *}$ \\
& $(0.128)$ & $(0.134)$ \\
\hline Constant & -3.857 & -1.164 \\
& $(2.859)$ & $(2.395)$ \\
\hline Wald chi2 (9) & 18.101 & 25.567 \\
\hline p-value & .034 & .002 \\
\hline & 97 & 97 \\
\hline
\end{tabular}

$* * * \mathrm{p}<0.001,{ }^{*} \mathrm{p}<0.01,{ }^{*} \mathrm{p}<0.05$ - two-tailed tests; Robust standard errors in parentheses 
Table 3: Negative Binomial Regression Analyses - Colleagues Supported in Collaboration

\begin{tabular}{|c|c|c|}
\hline & $\begin{array}{c}\text { Model 3: Colleagues } \\
\text { Supported in Collaboration - } \\
\text { Different Departments }\end{array}$ & $\begin{array}{c}\text { Model 4: Colleagues } \\
\text { Supported in Collaboration - } \\
\text { Different Salary Grade }\end{array}$ \\
\hline Implicit Collaborative Self- & $0.314^{*}$ & $0.357^{*}$ \\
Concept & $(0.154)$ & $(0.170)$ \\
\hline Explicit Collaborative Self- & -0.046 & 0.081 \\
Concept & $(0.073)$ & $(0.076)$ \\
\hline Gender - Male & 0.458 & $0.588^{* *}$ \\
& $(0.235)$ & $(0.219)$ \\
\hline Ethnicity - White & 0.094 & 0.367 \\
& $(0.333)$ & $0.265)$ \\
\hline Education - MD / PhD & 0.148 & $0.569^{*}$ \\
& $(0.221)$ & $(0.246)$ \\
\hline Log Tenure & 0.201 & 0.281 \\
& $(0.149)$ & $0.145)$ \\
\hline Log Salary Grade & $2.892^{* *}$ & $1.105^{*}$ \\
& $(0.879)$ & $0.472)$ \\
\hline Function - R\&D & 0.055 & $-1.585^{* * *}$ \\
& $(0.210)$ & $(0.265)$ \\
\hline Task Interdependence & 0.124 & -0.078 \\
& $(0.104)$ & $(0.124)$ \\
\hline Constant & $-13.118^{* * *}$ & $-5.461^{* *}$ \\
& $(3.736)$ & $(1.874)$ \\
\hline Wald chi2 (9) & 50.357 & 70.021 \\
\hline p-value & $9.23 \mathrm{e}-08$ & $1.51 \mathrm{e}-11$ \\
\hline Number of Observations & 106 & 106 \\
\hline
\end{tabular}

${ }^{* * *} \mathrm{p}<0.001,{ }^{* *} \mathrm{p}<0.01,{ }^{*} \mathrm{p}<0.05$ - two-tailed tests; Robust standard errors in parentheses 
Table 4. Dyad-Level Interaction - Horizontal Boundary Spanning

Conditional Log-Odds of Directed Tie Between Dyadic Pair Model 5 (Exponential Random Graph Model)

\begin{tabular}{|c|c|c|c|c|c|}
\hline $\begin{array}{c}\text { Explanatory } \\
\text { variables }\end{array}$ & $\begin{array}{l}\text { Coefficient } \\
\text { / Standard } \\
\text { Error }\end{array}$ & $\begin{array}{c}\text { Convergence } \\
\text { Statistic } \\
\text { (t-ratio) }\end{array}$ & $\begin{array}{l}\text { Explanatory } \\
\text { variables } \\
\text { (continued) }\end{array}$ & $\begin{array}{c}\text { Coefficient } \\
\text { / Standard } \\
\text { Error }\end{array}$ & $\begin{array}{c}\text { Convergence } \\
\text { Statistic } \\
\text { (t-ratio) }\end{array}$ \\
\hline $\begin{array}{l}\text { Structural } \\
\text { Covariates: }\end{array}$ & & & $\begin{array}{c}\text { Dyadic } \\
\text { Covariates: }\end{array}$ & & \\
\hline Arc & $\begin{array}{c}-9.13 * * * \\
(1.69)\end{array}$ & $.018^{\wedge}$ & Same Function & $\begin{array}{l}.057 \\
(.105)\end{array}$ & $-.009^{\wedge}$ \\
\hline Reciprocity & $\begin{array}{c}2.51 * * * \\
(.267)\end{array}$ & $.042^{\wedge}$ & Same Gender & $\begin{array}{l}.306^{*} \\
(.110)\end{array}$ & $.049^{\wedge}$ \\
\hline $\begin{array}{c}\text { Path Closure } \\
\text { (AT-T) }\end{array}$ & $\begin{array}{c}1.04 * * * \\
(.092)\end{array}$ & $.023^{\wedge}$ & Same Educ. - & $.279^{*}$ & $.027^{\wedge}$ \\
\hline $\begin{array}{c}\text { Cyclic Closure } \\
\text { (AT-C) }\end{array}$ & $\begin{array}{c}-.478 * * * \\
(.104)\end{array}$ & $.040^{\wedge}$ & $\mathrm{MD} / \mathrm{PhD}$ or not & (.123) & \\
\hline Multiple Two- & $-.173 * * *$ & $.016^{\wedge}$ & Same Ethnicity & .228 & $-.039^{\wedge}$ \\
\hline $\begin{array}{l}\text { Paths (A2P-T) } \\
\text { Initiator }\end{array}$ & $(.028)$ & & - White or other & $(.118)$ & \\
\hline $\begin{array}{l}\text { Covariates: } \\
\text { ICS }\end{array}$ & $\begin{array}{l}.046 \\
(.103)\end{array}$ & $-.043^{\wedge}$ & Same Location & $\begin{array}{c}1.24^{* * * *} \\
(.104)\end{array}$ & $.017^{\wedge}$ \\
\hline ECS & $\begin{array}{l}.032 \\
(.040)\end{array}$ & $.010^{\wedge}$ & $\begin{array}{l}\text { Different } \\
\text { Department }\end{array}$ & $\begin{array}{l}-.146 \\
(.115)\end{array}$ & $-.039^{\wedge}$ \\
\hline Log Sal. Grade & $\begin{array}{l}.172 \\
(.232)\end{array}$ & $.018^{\wedge}$ & Different & .104 & $.016^{\wedge}$ \\
\hline Log Tenure & $\begin{array}{l}-.008 \\
(.069)\end{array}$ & $-.001^{\wedge}$ & $\begin{array}{l}\text { Department } x \\
\text { Initiator's ICS }\end{array}$ & (.107) & \\
\hline Task Interdep. & $\begin{array}{l}-.098^{*} \\
(.047)\end{array}$ & $.028^{\wedge}$ & Different & $.213^{*}$ & $.039^{\wedge}$ \\
\hline $\begin{array}{c}\text { Target } \\
\text { Covariates: }\end{array}$ & & & $\begin{array}{l}\text { Department } x \\
\text { Target's ICS }\end{array}$ & $(.084)$ & \\
\hline$\underline{\text { ICS }}$ & $\begin{array}{l}.164 \\
(.089)\end{array}$ & $-.013^{\wedge}$ & & & \\
\hline ECS & $\begin{array}{l}-.017 \\
(.044)\end{array}$ & $.011^{\wedge}$ & & & \\
\hline Log Sal. Grade & $\begin{array}{l}.958^{* *} \\
(.301)\end{array}$ & $.019^{\wedge}$ & & & \\
\hline Log Tenure & $\begin{array}{l}.204 * * \\
(.076)\end{array}$ & $.015^{\wedge}$ & & & \\
\hline Task Interdep. & $\begin{array}{l}.025 \\
(.049)\end{array}$ & $.053^{\wedge}$ & & & \\
\hline
\end{tabular}


Table 5. Dyad-Level Interaction - Vertical Boundary Spanning

Conditional Log-Odds of Directed Tie Between Dyadic Pair Model 6 (Exponential Random Graph Model)

\begin{tabular}{|c|c|c|c|c|c|}
\hline $\begin{array}{c}\text { Explanatory } \\
\text { variables }\end{array}$ & $\begin{array}{c}\text { Coefficient } \\
\text { / Standard } \\
\text { Error }\end{array}$ & $\begin{array}{l}\text { Convergence } \\
\text { Statistic } \\
\text { (t-ratio) }\end{array}$ & $\begin{array}{l}\text { Explanatory } \\
\text { variables } \\
\text { (continued) }\end{array}$ & $\begin{array}{l}\text { Coefficient } \\
\text { / Standard } \\
\text { Error }\end{array}$ & $\begin{array}{c}\text { Convergence } \\
\text { Statistic } \\
\text { (t-ratio) }\end{array}$ \\
\hline $\begin{array}{l}\text { Structural } \\
\text { Covariates: }\end{array}$ & & & $\begin{array}{c}\text { Dyadic } \\
\text { Covariates: }\end{array}$ & & \\
\hline Arc & $\begin{array}{c}-9.47^{* * * *} \\
(1.60)\end{array}$ & $-.021^{\wedge}$ & Same Function & $\begin{array}{l}.044 \\
(.104)\end{array}$ & $-.021^{\wedge}$ \\
\hline Reciprocity & $\begin{array}{c}2.51 * * * \\
(.294)\end{array}$ & $-.038^{\wedge}$ & Same Gender & $\begin{array}{l}.272 * \\
(.113)\end{array}$ & $-.052^{\wedge}$ \\
\hline $\begin{array}{c}\text { Path Closure } \\
\text { (AT-T) }\end{array}$ & $\begin{array}{c}1.04 * * * \\
(092)\end{array}$ & $-.055^{\wedge}$ & Same Educ - - & $295^{*}$ & $015^{\wedge}$ \\
\hline $\begin{array}{c}\text { Cyclic Closure } \\
\text { (AT-C) }\end{array}$ & $\begin{array}{c}-.479 * * * \\
(.101)\end{array}$ & $-.053^{\wedge}$ & $\mathrm{MD} / \mathrm{PhD}$ or not & $(.122)$ & \\
\hline Multiple Two- & $-.171 * * *$ & $-.029^{\wedge}$ & Same Ethnicity & .218 & $-.058^{\wedge}$ \\
\hline $\begin{array}{l}\text { Paths (A2P-T) } \\
\text { Initiator }\end{array}$ & $(.033)$ & & - White or other & $(.115)$ & \\
\hline $\begin{array}{c}\text { Covariates: } \\
\text { ICS }\end{array}$ & $\begin{array}{l}.020 \\
(.102)\end{array}$ & $.012^{\wedge}$ & Same Location & $\begin{array}{c}1.26^{* * *} \\
(.114)\end{array}$ & $-.026^{\wedge}$ \\
\hline$\underline{E C S}$ & $\begin{array}{c}.030 \\
(.040)\end{array}$ & $-.022^{\wedge}$ & $\begin{array}{c}\text { Different Salary } \\
\text { Grade }\end{array}$ & $\begin{array}{l}.028 \\
(.114)\end{array}$ & $-.040^{\wedge}$ \\
\hline Log Sal. Grade & $\begin{array}{c}.202 \\
(.221)\end{array}$ & $-.020^{\wedge}$ & Different Salary & $.229 *$ & $-.023^{\wedge}$ \\
\hline Log Tenure & $\begin{array}{l}.018 \\
(.075)\end{array}$ & $-.089^{\wedge}$ & $\begin{array}{c}\text { Grade x } \\
\text { Initiator's ICS }\end{array}$ & (.111) & \\
\hline $\begin{array}{c}\text { Task Interdep. } \\
\text { Target }\end{array}$ & $\begin{array}{l}-.108^{*} \\
(.050)\end{array}$ & $-.012^{\wedge}$ & $\begin{array}{l}\text { Different Salary } \\
\text { Grade x }\end{array}$ & $\begin{array}{l}.310^{*} \\
(.119)\end{array}$ & $.008^{\wedge}$ \\
\hline $\begin{array}{l}\text { Covariates: } \\
\text { ICS }\end{array}$ & $\begin{array}{l}.010 \\
(.122)\end{array}$ & $-.060^{\wedge}$ & Target's ICS & & \\
\hline ECS & $\begin{array}{l}-.019 \\
(.039)\end{array}$ & $-.041^{\wedge}$ & & & \\
\hline Log Sal. Grade & $\begin{array}{c}.983 * * * \\
(.286)\end{array}$ & $-.023^{\wedge}$ & & & \\
\hline Log Tenure & $\begin{array}{l}.199^{*} \\
(.078)\end{array}$ & $.003^{\wedge}$ & & & \\
\hline Task Interdep. & $\begin{array}{c}.029 \\
(.045) \\
\end{array}$ & $-.005^{\wedge}$ & & & \\
\hline
\end{tabular}


Figure 1: Illustration of Implicit Association Test Procedure

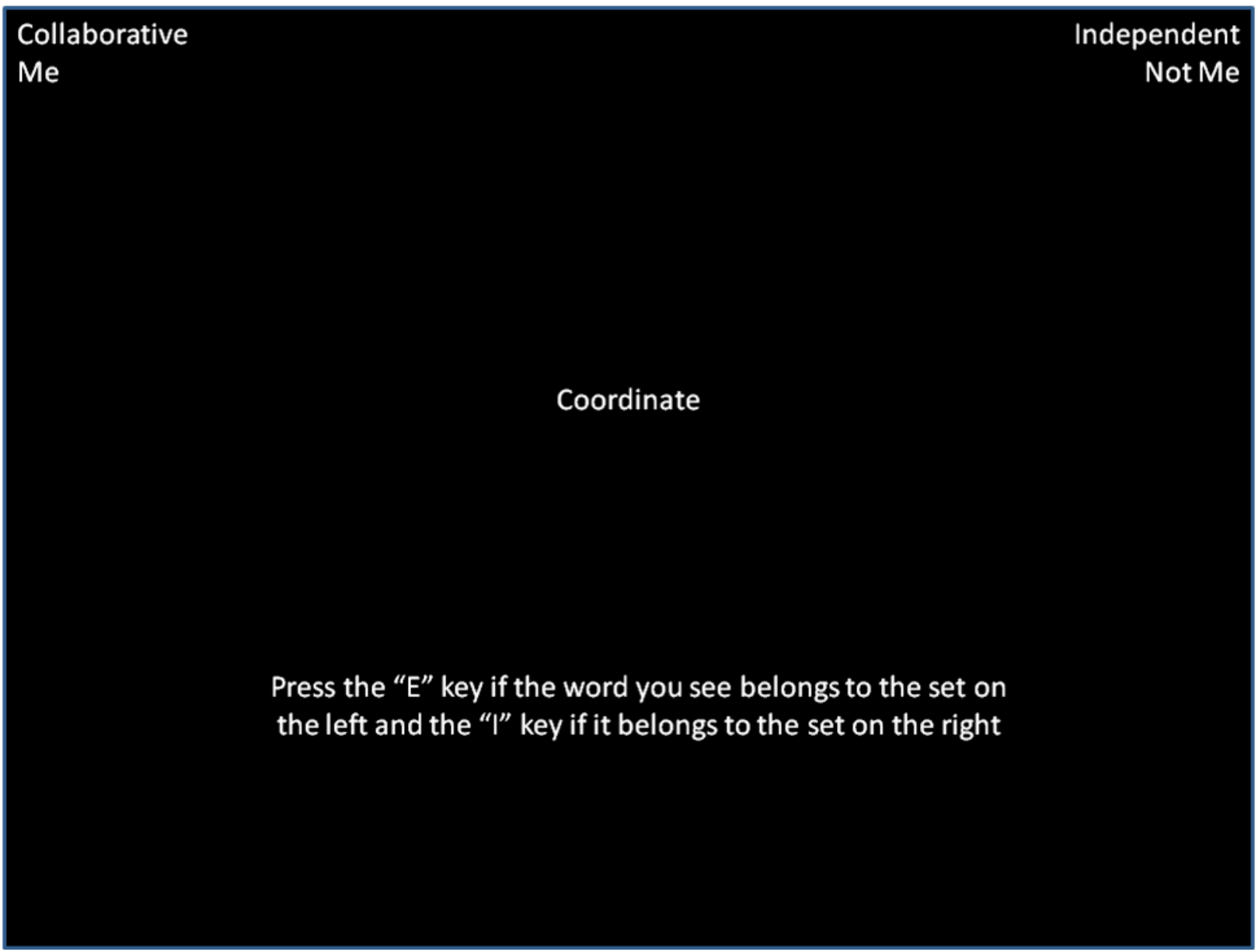


Figure 2: Correlation Between Explicit and Implicit Measures

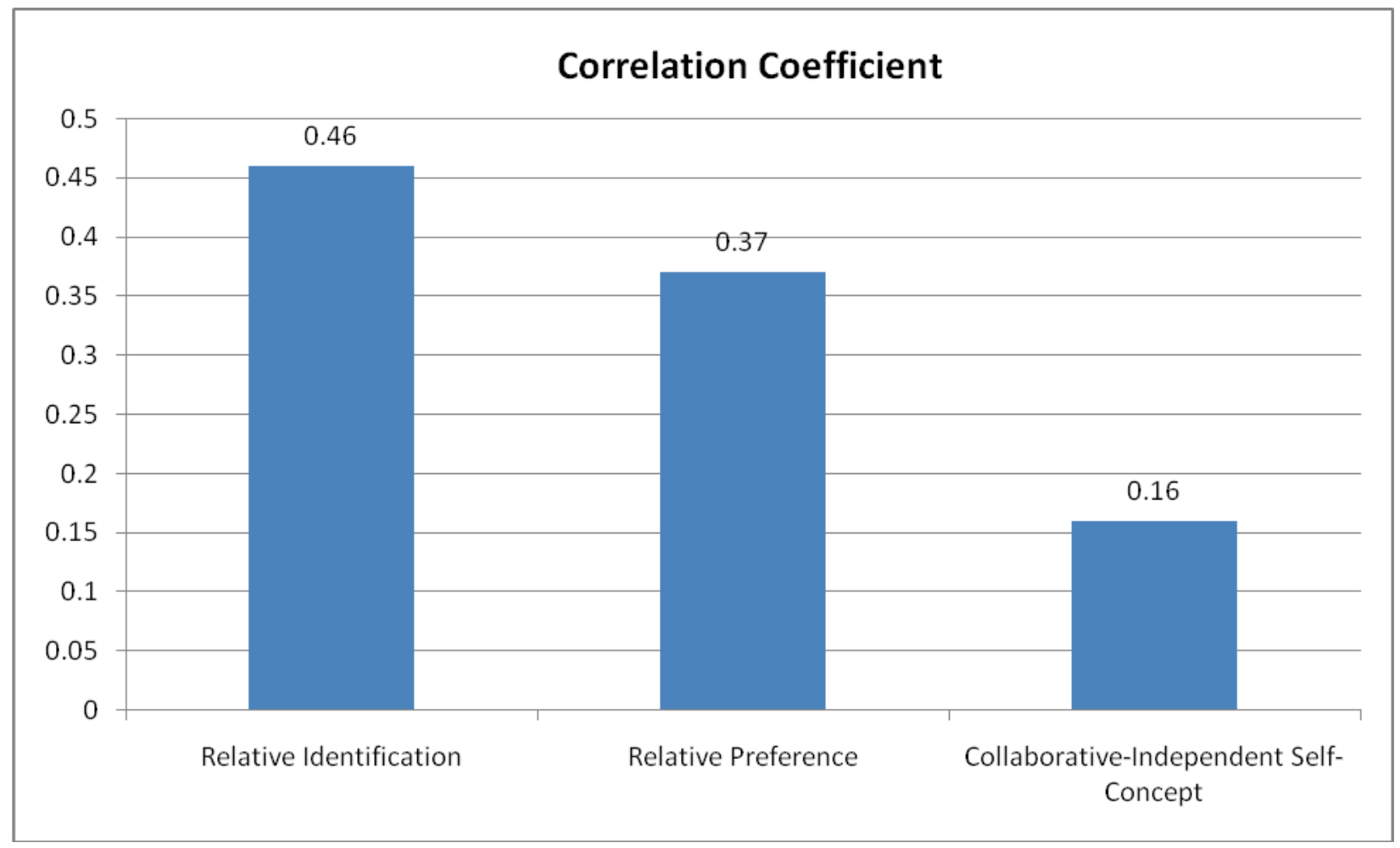


Figure 3: Distribution of Explicit Collaborative-Independent Self-Concept Measure

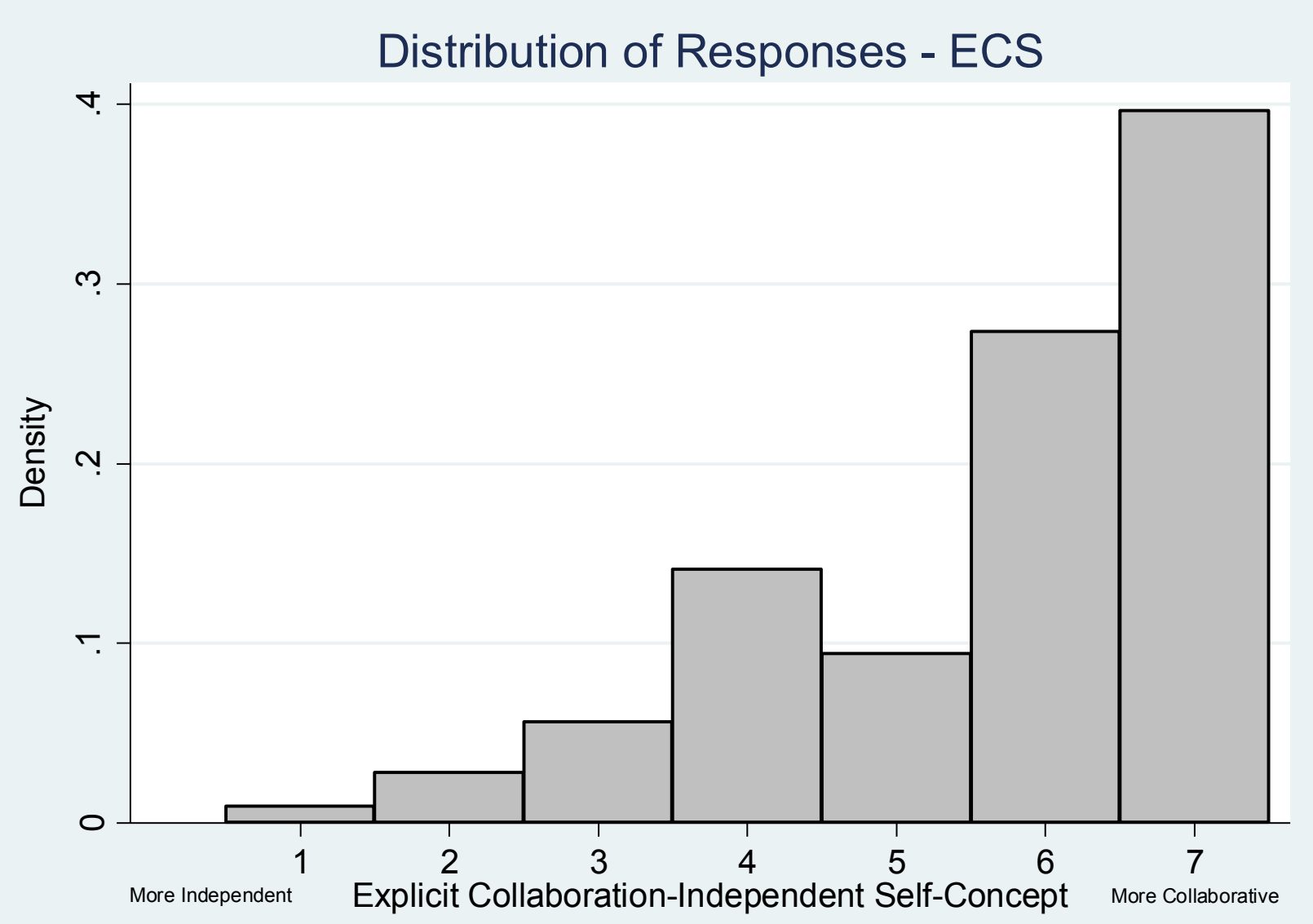


Figure 4: Distribution of Implicit Collaborative-Independent Self-Concept Measure

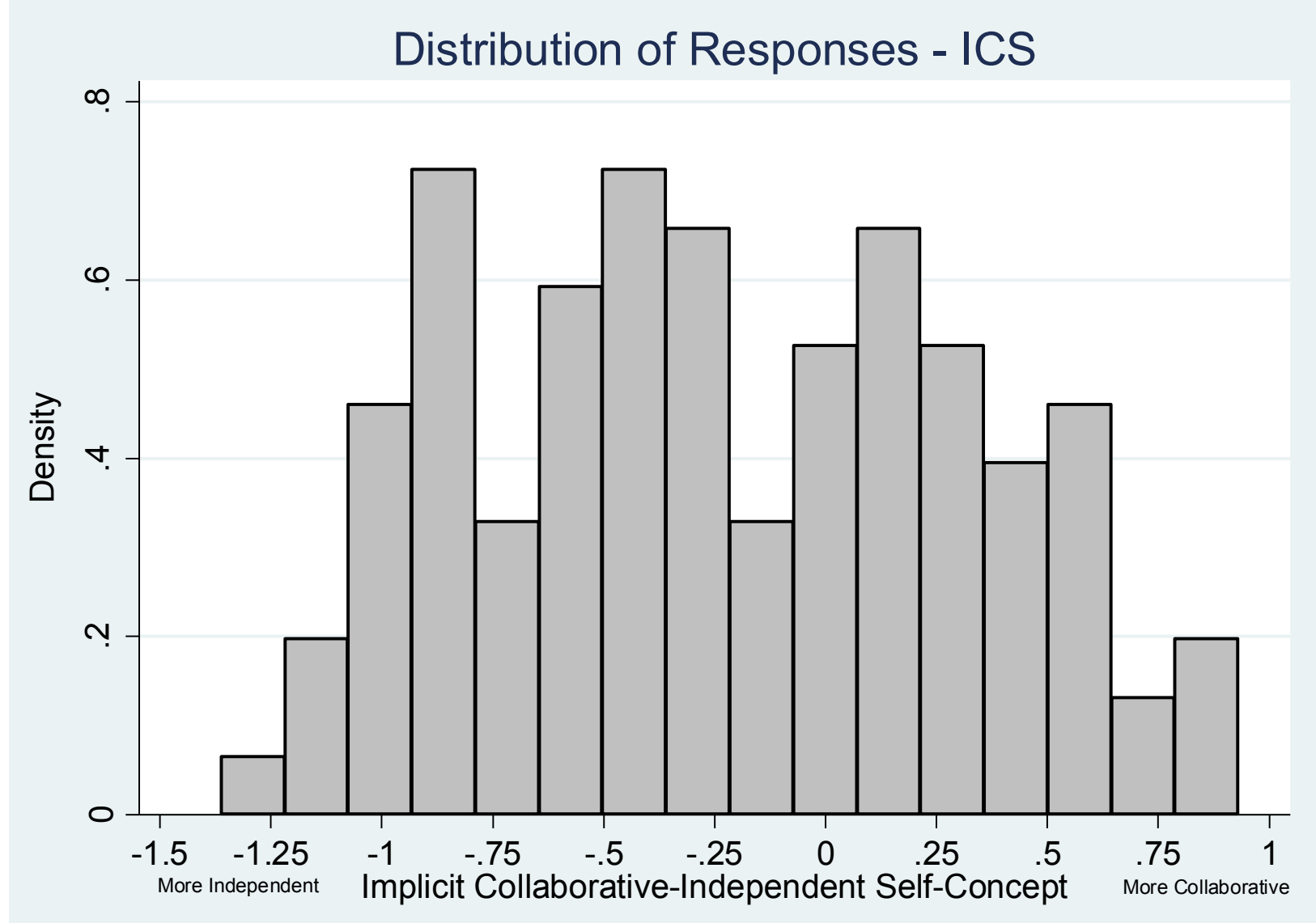

